NBER WORKING PAPER SERIES

\title{
UNEMPLOYMENT VS. MISMATCH \\ OF TALENTS: RECONSIDERING \\ UNEMPLOYMENT BENEFITS
}

\author{
Ramon Marimon \\ Fabrizio Zilibotti
}

Working Paper 6038

\author{
NATIONAL BUREAU OF ECONOMIC RESEARCH \\ 1050 Massachusetts Avenue \\ Cambridge, MA 02138 \\ May 1997
}

Zilibotti acknowledges the Centre de Recerca en Economia Internacional for financial support and the European Forum of the EUI for kind hospitality. This paper is part of NBER's research program in Economic Fluctuations and Growth. Any opinions expressed are those of the authors and not those of the National Bureau of Economic Research.

(C) 1997 by Ramon Marimon and Fabrizio Zilibotti. All rights reserved. Short sections of text, not to exceed two paragraphs, may be quoted without explicit permission provided that full credit, including $(\mathcal{O}$ notice, is given to the source. 
Unemployment vs. Mismatch of Talents:

Reconsidering Unemployment Benefits

Ramon Marimon and Fabrizio Zilibotti

NBER Working Paper No. 6038

May 1997

JEL Nos. J64, J65, D33

Economic Fluctuations and Growth

\begin{abstract}
We develop an equilibrium search-matching model with risk-neutral agents and two-sided ex ante heterogeneity. Unemployment insurance has the standard effect of reducing employment, but also helps workers to get a suitable job. The predictions of our simple model are consistent with the contrasting performance of the labor market in Europe and the US in terms of unemployment, productivity growth and wage inequality. To show this, we construct two fictitious economies with calibrated parameters which only differ by the degree of unemployment insurance and assume that they are hit by a common technological shock which enhances the importance of mismatch. This shock reduces the proportion of jobs which workers regard as acceptable in the economy with unemployment insurance (Europe). As a result, unemployment doubles in this economy. In the laissez-faire economy (US), unemployment remains constant, but wage inequality increases more and productivity grows less due to larger mismatch. The model can be used to address a number of normative issues.
\end{abstract}

Ramon Marimon

Department of Economics

European University Institute

Badia Fiesolana

I-50016 S. Domenico di Fiesole (FI)

ITALY

and NBER

marimon@datacomm.iue.it
Fabrizio Zilibotti

Facultat d'Economiques

Universitat Pompeu Fabra

R. Trias Fargas, 25-27

08005 Barcelona

SPAIN 


\section{Introduction}

This paper develops a general equilibrium model of the labor market. We show how a simple model with search and productivity-matching frictions, and no other rigidities, can capture unemployment, productivity and wage inequality patterns associated with the contrasting evolution of labor markets in Europe and US in the last twenty years. The main idea is that an episode of unexpected skilledbiased technological change can generate very different responses with permanent effects in two economies which have only one institutional difference: the degree of unemployment insurance coverage. We also analyze the normative and distributional implications of introducing or changing a system of unemployment insurance. In the rest of this introduction we informally discuss these issues and relate them to the existing literature.

\subsection{The contrast between Europe and US in the last two decades.}

The economic performance of Western Europe and the United States has been characterized by three important contrasting elements. First, unemployment has risen dramatically in Western Europe, whereas in the United States it exhibits no trend. Second, productivity per worker has grown significantly faster in Europe than in the US. Third, wage inequality has increased in the US but not in Europe, and has fallen in some European countries.

European unemployment increased, from average $4 \%$ in the early 70 's, to more than $11 \%$ in the mid 80 's and remained persistent at very high levels thereafter; in the US the unemployment rate was around $5 \%$ in 1975 , and around $6 \%$ in 1994 . The rising level of unemployment in Europe has been associated with longer duration of unemployment, and with growing shares of long-term unemployed. Alogoskoufis et al. (1995) document that the flows of people out of unemployment halved in the period 1979-1988, while the flows into unemployment have changed relatively little during that period. In the US, to the opposite, both the inflows and outflows are stationary. The unemployment gap notwithstanding, total GDP growth in Europe has been similar to that of the US in the last 25 years. In the period 1975-93 the GDP growth rate of the US has been $2.6 \%$ per year, about the same as that of Germany (2.5\%), France (2.4\%), Italy (2.8\%) and Spain (2.5\%), although some European countries have experienced lower growth rates; e.g. Sweden (1.5\%) - 
where the unemployment rate has been low until the beginning of the 90 's - and the United Kingdom (1.9\%). These two facts, different employment rates and similar growth rates, imply large differences in productivity growth: in the period 1975-94 the average gap between the growth rate of output per worker in the European Union and the United States has been above one per cent per year.

While in Europe the main social concern has been increasing unemployment, in the US it has been increasing wage inequality, which has produced the so-called 'class of working-poor' (see, among others, Katz et al., 1995, and Freeman, 1995 and 1996). ${ }^{1}$ Although part of this inequality has to do with the increasing gap between the earnings of qualified (college graduates, experienced workers) vs. non-qualified groups, it has been also noted that in the US wage differences have grown not only across groups, i.e. between workers of different skill levels, but also within groups, i.e. among equally skilled workers (Levy and Murnane, 1992). From a comparative perspective, Alogoskoufis et al. (1995) observe that 'while the average duration of unemployment is very short in the United States, this does not imply that the lifetime labor market experience of a typical American unemployed worker is necessarily any better than his European counterpart.' (p. 13).

It is common to associate the different performance of US and European labor markets with large differences in market flexibility. The first aim of this paper is to show that a simple standard general equilibrium model, with a minimal degree of institutional differences across economies - the level of unemployment benefits - is consistent with the large differences documented above. From a normative standpoint, the same common view has led to regard the contrast between US and European employment record as an uncontrovertible prescription to reform the European welfare state in the direction of the US more flexible labor market. The 'working poor problem' is sometimes argued to be 'the price to pay'. These are important and delicate social issues, which cannot be properly addressed without an explicit theory. This is the second aim of this paper: to develop a model that will allow us to study these normative issues in detail. In particular, our theory not only looks at whether people are employed or unemployed, but also at how they are employed and, in doing that, it reassesses the role of a widespread social contract:

\footnotetext{
${ }^{1}$ Freeman (1996) writes that 'in Western Europe, a male worker in the bottom of the earnings distribution earns $68 \%$ of the median worker's income; in Japan, that male worker earns $61 \%$ of the median. In the United States, he earns $38 \%$ of the median. And a comparison of purchasing power parity reveals that... low paid German workers earn 2.2 times more than low-paid American workers.'
} 
unemployment protection.

\subsection{Unemployment insurance reconsidered.}

A central aspect of our analysis is that unemployment benefits can provide the necessary insurance to give time to the unemployed to search not just for a job, but for the right job. Unemployment is an economic issue insofar as it implies a waste of productive resources; but mismatch of talents and jobs is also a misallocation of resources. This has been recognized, for example, by Solow (1987), who suggests that we should count as (involuntarily) unemployed all agents whose 'marginal value of leisure is less than the going real wage in occupations for which they are qualified', a definition which 'covers both the skilled mechanic who does not take work as a sweeper and the one who does' (p. 33). In a labor market with search frictions, the existence of unemployment benefits tends to reduce job mismatches. In particular, unemployed without a 'safety net' may accept unsuitable jobs and form what can be identified with a class of 'working poor.' To the opposite when this 'safety net' is too high, workers become too selective, and reject matches which would increase (the present discounted value of) total output. ${ }^{2}$

The extent of unemployment insurance has also important distributional implications. Increasing insurance typically make the unemployed better off, while the employed workers may either gain or loose. Wright (1986) analyzes the trade-off faced by employed workers between the cost of paying taxes to transfer income to the unemployed and the insurance value of receiving benefits in case they loose the current employment. More recently, Hassler and Rodriguez Mora (1997) consider political economy issues, and show that due to insurance reasond the degree of unemployment insurance chosen by a society through a voting system depends on the turnover degree. In this paper we show that even if a standard insurance motive is absent (agents are risk-neutral) workers may support some degree of benefits provision because this enhances the allocation of talents and increases the equilibrium wage rate of all types of workers. Thus, benefits imply both some redistribution from employed to unemployed workers and some redistribution from firms' profits

\footnotetext{
${ }^{2}$ The result that unemployment insurance reduces mismatch can also be found in partial equilibrium search models in which workers face an exogenous wage offer distribution. For instance, Rendon, 1996, shows that the degree to which agents are choosy in the labor search process depends on their accumulated wealth and on the level of insurance. However, while our model allows to analyze how workers' decisions interact with the process of job creation, this cannot be done in a partial equilibrium framework.
} 
to employed workers (through wage increase). The net effects on the welfare of the employed workers is ambiguous, and the 'working poor' always benefit more than the rich worker from the presence of insurance. Therefore, unemployment benefits can receive the political support of all, or part of, workers, in addition to the support of the unemployed.

\subsection{The basic features of our theory.}

The framework for our positive and normative analysis is a model which has two basic features: search-matching frictions and skill-biased technical change.

The importance of costs associated with the matching process between workers and firms in the labor market has been recognized since the work of Diamond (1982), Mortensen (1982) and Pissarides (1985, 1990). Using the basic setup of these models, we add the feature that workers and firms are ex-ante heterogeneous. Differently from previous papers (e.g. Lockwood, 1986; Moscarini, 1995), this heterogeneity does not mean that some workers have better skill endowments than others (either innate or acquired through education, family environment, etc.), or that there is imperfect information about the productivity of a worker-job assignment (as in Jovanovic, 1979), but takes the form of each worker being more suitable to some jobs than to others. These differences are observable. A worker who performs these - well matched - tasks has a higher productivity, and this is reflected by a higher wage in equilibrium. The main implication of this heterogeneity is that it allows us to model mismatch. Since to find a job is a time consuming process, workers (and firms) typically accept to take jobs which are not the best possible for their individual characteristics.

A number of recent works have argued that the increase in wage inequality in US and unemployment in Europe is the result of a process of technical change that has been biased in favor of skilled workers, namely has increased the relative productivity of qualified vs. non-qualified jobs (see, for example, Krugman, 1994, Wood, 1994 and Manacorda and Petrongolo, 1996). Similarly, Krusell et al. (1995) postulate a relation of complementarity between capital and skilled workers, and argue that during the last two decades the price of capital has fallen relative to that of labor, inducing firms to switch towards techniques which are intensive in capital and skilled workers. We build on this idea that skilled-biases technical change is a characteristic of the growth experience of the OECD countries in the last twenty years to explain 
not only increasing wage inequality in US, but also increasing unemployment and productivity in Europe. ${ }^{3}$ In our theory, this takes the particular form of an increase in the importance of mismatch. In other words, we postulate that over the last decades the gap between the productivity of a given worker in a job for which he is qualified, and a job for which the same worker is not qualified has increased.

A driving force, for some of our results, is that workers may become more selective in job search in response to a skilled-biased technological shock. How selective they become, depends on the extent of unemployment insurance. If they become more selective, this changes the equilibrium distribution of talents that firms face and, therefore, their strategies regarding the creation of vacancies.

Our assumption that skilled-biased technological change, as an engine of growth, is a characteristic of last two decades is consistent with Greenwood, Hercowitz and Krusell (1997) findings for the US. They show that, starting in the mid-seventies, there is an acceleration of investment-specific technological change together with a 'dramatic downturn in total factor productivity.' In other words, the rapid growth of the Second Post-War years experienced by US and, presumably, Western Europe is due, to a large extent, to total factor productivity. This is consistent with a standard neoclassical growth model, which predicts such a rapid growth in the transitional phase, when the capital stock is low and highly productive. In the last quarter of century, however, the nature of the growth process seems to have changed, generating new phenomena such as increasing wage inequality in the US and unemployment in Europe, as we described them above. Motivated by the evidence that the 70's are a turning point in the experience of the industrialized country, in this paper we restrict our attention to the events of the most recent years.

We construct two fictitious economies, equal in all except that one grants and the other does not grant unemployment benefits, and choose parameters such that the two economies have fairly similar (steady-state) unemployment rates. Then, we simulate the response of these fictitious economies as they are hit by a common unexpected permanent shock, and contrast the results with the observed patterns

\footnotetext{
${ }^{3}$ Most existing theories which explain the different behavior of European vs. US labor markets as determined by skill-biased technical change plus a different degree of labor market inflexibility have problematic predictions about the incidence of unemployment for different groups of workers. From the predicitions of these theories, we would expect that the unskilled-to-skilled unemployment ratio should be larger in Europe than in the United States, while there is no evidence of this in the data (see Alogoskoufis et al., 1995). Furthermore, as observed by Acemoglu (1996c), skilled unemployment has also increased over the past two decades. Our theory, as we will see, is not subject to this criticism.
} 
of the US and European economies between the 70's and the 90's. The nature of the shock is to increase labor productivity in both economies so that the relative productivity of 'qualified' vs. 'unqualified' jobs raises. In the new steady-states, the unemployment rate doubles in the economy with the more generous unemployment insurance, whereas it remains approximately constant in the other. Furthermore, the average duration of the unemployment spells increases in the 'welfare state' economy, whereas it does not change in the 'laissez-faire' economy. However, not all economic indicators are favorable to the laissez-faire economy. First, the growth of productivity per worker is much higher with than without unemployment benefits - In fact, after the shock the simulated welfare state economy has a steady-state level of total output which is slightly higher than that of the laissez-faire economy. The former, on the other hand, experiences a sharp transitional drop in output, following the skilled-biased productivity shock which the latter does not suffer. Third, wage inequality increases in the economy without benefits, whereas it changes only marginally in the one with benefits.

We also consider normative and distributional issues. In our model, there are several sources of inefficiency. First, like in standard models of job creation and job destruction with homogeneous workers, there are trading externalities which in generic economies are not internalized throughout the wage negotiation between workers and firms (see Pissarides, 1990). Second, the heterogeneity introduces the problem of assigning workers to jobs, which is not efficiently solved, in general, through a decentralized procedure. The first source of inefficiency is well understood. In particular, as it has been shown by Hosios (1990), when workers' bargaining power (their share in the Nash bargaining problem) is equal to 'the elasticity' of matching respect to unemployment, then the decentralized equilibrium is efficient. With respect to the standard search externality, our model shares the standard properties. The second form of inefficiency has been less studied, although, recently Mortensen (1996a) has shown that in the Mortensen and Pissarides (1994) model with ex-post heterogeneity, the Hosios condition is also necessary and sufficient for an efficient assignment of workers to jobs in equilibrium. This paper shows that this generalized welfare theorem of search equilibria is also satisfied in a model of $e x$ ante heterogeneity. We also show how previous results showing that equilibrium job assignments were generically inefficient (e.g., Diamond, 1981, and Sattinger, 1995) relied on other forms of market failure.

If there are no competitive forces relating -and equating- workers' bargaining 
power with 'the elasticity' of matching respect to unemployment, then the set of matches which agents regard as acceptable in a decentralized equilibrium does not -generically- coincide with that which maximizes the present discounted value of aggregate output. In particular, when workers have a high bargaining power, they are too choosy, and reject jobs which would increase the present discounted value of output. Viceversa, when workers have a low bargaining power, they tend to accept too many jobs, and there is excess mismatch. ${ }^{4}$

In addressing the distributional issues, we show that when unemployment benefits are financed through uniform lump-sum taxes, workers can be ranked according to their preferences regarding unemployment benefits. In particular, either there is unanimous agreement on a reform of the level of unemployment benefits, or unemployed, and possibly 'the working poor,' will favor the reform against the interests of the 'rich workers' and firm owners. We also show, that for a large set of parameters - including the case in which the Hosios-Pissarides efficiency condition is satisfied - a union acting on behalf of all the workers (unemployed and all employed), will vote for a positive level of unemployment benefits. Some of these welfare results are illustrated in our calibrations. For example, with our parameters, $55 \%$ of the workforce would have chosen in the 70's an economy with positive unemployment benefits.

\subsection{Some related literature.}

Among the vast literature which has studied the empirical issues considered in this paper, the three contributions which are methodologically closest to our work are Mortensen and Pissarides (1994), Ljungqvist and Sargent (1996) and Acemoglu (1997).

Mortensen and Pissarides (1994) introduce ex-post heterogeneity in the standard equilibrium search model. In their model, how suitable a worker is for a job is observed after the match has occurred and the vacancy filled. The scope of the analysis of the authors is very different from ours (they study job creation and

\footnotetext{
${ }^{4} \mathrm{By}$ 'generic' inefficiency, we mean that if we consider the parameters of the model (in particular, workers' share of the surplus and the elasticities of the matching function), then only for a specific values (i.e., a measure-zero event) is the search-matching equilibrium efficient. Recently, Moen (1994) and Shimer (1995) have shown that the 'right bargaining power' which guarantees efficiency emerges endogenously as the unique equilibrium solution in a model were workers face different labor markets. Mortensen (1996a) shows that this result also generalizes to the Mortensen and Pissarides (1994) model with job assignments (see also Acemoglu and Shimer, 1997)
} 
destruction patterns through the business cycle and ignore the range of positive and normative issues addressed here). But their model shares some basic features with ours. The main difference is that we assume the match-specific productivity shock is realized as the worker and the firm interview, before the hiring decision. Many of the implications of our theory would in fact remain true if we assumed ex-post rather than ex-ante heterogeneity (e.g. the economy with insurance would have less wage inequality and higher unemployment). The main difference is that the model of Mortensen and Pissarides with ex-post heterogeneity would predict that unemployment is higher in the economy with larger insurance mainly because of higher separation rates, while in our model this is entirely the effect of lower hiring rates. In the data, both unemployment inflow and outflow rates are larger in the US than in Europe, and the difference of larger magnitude is in hiring rates. (see Alogoskoufis et al., 1995). Moreover, the main change observed in Europe starting from the late 70's is a drop in the hiring rates, while separation rates have remained fairly stable. The predictions yielded by the model with ex-post heterogeneity would therefore be less consistent with the empirical evidence.

Ljungqvist and Sargent (1996) is similar in scope and to some extent complementary to our work. This paper treats the process of job creation as exogenous and stresses the distortive effects of benefits on the incentives to search. A calibration of the model shows that although unemployment benefits have moderate effects on the aggregate unemployment rate in a situation of 'low economic turbulence' (the sixties) it can have larger effects as this turbulence increases (the eighties). While this paper shows that wage rigidities are not needed to explain different labor market performances, it leaves open a number of questions. First, the main result relies on a shock (increasing variance of the loss of skill of workers upon separation) which is of difficult interpretation. Second, when the model is calibrated to obtain differential in unemployment rates similar to those observed between the US and Europe, it predicts hardly any difference between the average productivity per worker of the two economies.

In Acemoglu (1997) there are homogeneous workers and two types of firms: good and bad. In the decentralized equilibrium the share of bad jobs which are created is too high, and multiple equilibria are possible. An increase in minimum wages or unemployment benefit shifts the distribution towards good jobs increases unemployment and decreases wage inequality. This paper, like ours and in contrast with Ljungqvist and Sargent (1996), stresses the existence of channels through which to 
give workers some social insurance can be welfare-improving. Among the differences, while Acemoglu (1997) has interesting predictions about across-group wage inequality, our work has implications about within-group wage inequality. In this respect, our work is closer to Acemoglu (1996a) which is, however, different in other respects.

Among papers which do not adopt a search approach, Bertola and Ichino (1995) present a model in which workers have mobility costs and firms are subject to idiosyncratic temporary shocks. They argue that the volatility of firm-idiosyncratic shocks has increased in the last decades, originating asymmetric responses in 'rigid' and 'flexible' labor markets, consistent with the evidence of increasing unemployment in Europe and increasing wage inequality in North America. In this paper, large institutional differences between European and North American labor markets are at work. In particular, the action of unions in Europe sets wages abovethe level consistent with market clearing and artificially compresses the wage distribution. Moreover, firms are subject to prohibitive firing restrictions. In contrast, our paper aims at showing that the recent events can be obtained without relying on so many and important exogenous imperfections. ${ }^{5}$

Our paper can also be related to the growing literature which studies the importance of sectoral reallocation on unemployment and productivity (Lillien, 1982; Pheelan and Trejos, 1995). In a previous empirical work (Marimon and Zilibotti, 1997), we found that the extent of sectoral shifts in employment is positively correlated with the aggregate unemployment rate in a set of European countries. Although the model presented in this paper is highly stylized, and neither sectors nor industries are explicitly defined, mismatch can be regarded as the cost of shifting workers from one sector to another.

Finally, our paper is related to the existing literature that studies the efficiency properties of search-matching models (Diamond, 1981, Hosios, 1990, Mortensen 1996a and 1996c, Pissarides, 1990, and Sattinger, 1995).

The plan of the paper is as follows. Section 2 presents the model. Section 3 characterizes the equilibrium. Section 4 discusses efficiency issues. Section 5 presents the results of a calibration of the model, intended to reproduce the recent experience of Europe and the US. Section 6 concludes. An appendix contains the

\footnotetext{
${ }^{5}$ Other related work on a variety of labor market institutions includes Bertola (1996), Bertola and Rogerson (1996) and and Saint Paul (1997).
} 
technical details.

\section{The set-up of the model.}

\subsection{Ex-ante heterogeneity and search frictions.}

Consider an economy populated by a continuum of firms, workers and rentiers. Both firms and workers are heterogeneous. In particular, each worker has a different productivity depending on which firms he works with. Workers are uniformly distributed along a circle of unit length and the total mass of workers is one. At each moment of time a worker can be either employed with a certain firm or unemployed. All unemployed workers search for a job, and search effort is costless. Employed workers cannot switch from a job to another without becoming unemployed first (no on-the-job search). Firms are also uniformly distributed along the same circle of unit length, and the total mass of firms is $M>1$. At each moment of time a firm can have either a filled position, or an open vacancy, or be idle. An active firm with a filled position employs one worker, and obtains a revenue from selling the output which it produces. An active firm with an open vacancy pays a cost to keep the vacancy posted, and is not productive. Idle firms pay no cost and earn no revenue. We assume that $M$ is sufficiently large so that in any equilibrium which we will consider some firms of each type remain idle. The rentiers do not work, and each of them hold a balanced portfolio of shares of all $M$ firm. The income of a rentiers consists of dividends (possibly negative, in which case he is liable for the losses) plus an endowment flow. This endowment is sufficiently large to avoid limited liability issues. In the economy there is no physical capital, or other financial assets, and agents consume entirely the income which they receive period by period.

The productivity of an employed worker depends on the location of the firm where he takes employment, and decreases with the distance between the worker and the firm. Let $x:[0,1]^{2} \rightarrow\left[0, \frac{1}{2}\right]$ denote the function mapping locations of firm-worker pairs into distances. Thus, $x\left(j_{f}, j_{w}\right)$ is the length of the arc between the worker's location $\left(j_{w}\right)$ and the firm's location $\left(j_{f}\right)$. Next, we denote by $\eta$ : $\left[0, \frac{1}{2}\right] \rightarrow\left[\eta_{l}, \eta_{u}\right] \subset R^{+}$the function mapping distances between worker-firm pairs into productivities, where $0<\eta_{l}<\eta_{u}<\infty$, and assume that $\eta\left(\frac{1}{2}\right)=\eta_{l}, \eta(0)=\eta_{u}$, and $\eta(x)$ is continuous and non-increasing with $x$. Thus, we will interpret $x$ as a measure of mismatch between workers and firms, and label $\eta(x)$ as the mismatch 
function. An example of mismatch function which will be used in section 5 is:

$$
\eta(x)=\max \left\{\eta_{l}, \eta_{l}+a \cdot(1-\gamma x)\right\}
$$

where $a>0$ and $\gamma \geq 2$. In this case, a worker's productivity is linearly decreasing with distance, for all jobs located in an arc of length $\frac{2}{\gamma}$ centered about his location. If he takes any work outside that arc, the worker's productivity will be the lower bound, $\eta_{l}{ }^{6}$

Next, we describe the matching technology. We assume that workers and firms are randomly matched, i.e. any unemployed worker can meet and interview with any firm located at any point along the circle with the same probability. This means that firms do not sort workers ex-ante by specifying personal requirements when posting vacancies. The matching technology, $m=m(u, v)$, is assumed to have constant returns to scale to the total mass of unemployed $(u)$ and vacancies posted by firms $(v)$. All structural parameters of firms are identical, thus location is the only source of heterogeneity. By defining $q \equiv \frac{m}{v}$ and $\theta \equiv \frac{v}{u}$ we can write the matching function, $q=q(\theta)$, with the following standard assumptions:

$$
q=q(\theta), \quad q^{\prime}(\theta)<0, \quad \epsilon_{\theta} \equiv\left|\frac{d q}{d \theta} \frac{\theta}{q}\right|<1
$$

where $q$ represents, as usual, the probability for a firm posting a vacancy to meet a searching worker, and $\theta q(\theta)=\frac{m}{u}$ is the probability for a searching worker to meet a firm. Note that, due to ex-ante heterogeneity, only a fraction of the matches (interviews) which occur will be regarded as acceptable by workers and firms. The determination of this fraction will be part of the characterization of the equilibrium.

We restrict attention to symmetric (stationary) equilibrium distributions. In particular, we will assume initial distributions such that, at $t=0$ :

(i) the same proportion of workers are unemployed at all locations. This will imply that in equilibrium there is the same number of vacancies at all locations;

\footnotetext{
${ }^{6}$ An alternative way of modeling mismatch which would give almost identical results is to assume that all worker are equally productive upon hiring, and that there is a stochastic learning process which turns at each moment some employed worker into high productivity 'qualified' workers. The learning event is modeled as a Poisson process whose arrival rate is a decreasing function of the distance between each worker-firm pair. Note that an increase in relative productivity of 'qualified' vs. 'unqualified' workers in that version of the model is isomorphic to an increase in the parameter $a$ in equation (1). This will motivate our interpretation of changes in the mismatch function as episodes of 'skilled-biased' technical change. Details about the version of the model with stochastic learning are contained in a previous version of this paper available from the authors.
} 
(ii) the set of existing jobs, each of them involving a working-firm pair, are uniformly distributed on an interval of distances $[0, \hat{x}]$, with $\hat{x} \leq \frac{1}{2}$, and are independent and identically distributed with respect to the locations of workers and firms.

This will allow us to simply characterize initial distributions of workers by a real number, $u_{0} \in(0,1)$, denoting the total mass of unemployed, where it will be implicit that this is uniformly distributed over the circle.

Finally, we introduce the following notation:

$\bar{x}$ denotes the cut-off distance such that no match with productivity $\eta(x)$ will give rise to a job if $x>\bar{x}$

$d$ is the exogenous arrival rate of job separation, which is assumed to be the same for all matches. Once a job is terminated, the worker goes back to the pool of unemployed (at his original location), and the productivity which he had in the previous job is irrelevant to the effects of his future employment. The firm, in turns, becomes idle, and can decide whether or not to open a new vacancy;

$r$ is the interest rate;

$c$ is the hiring expenditure flow paid by firms while holding an open vacancy;

$b$ is the unemployment benefit plus the value of leisure.

\section{$2.2 \quad$ Asset price equations}

We will assume that there are no informational imperfections, namely both workers' and firms' locations are perfectly observed by both parties when they interview. All Bellman equations will be written as conditional only on the distance between the worker and the firm. We will conventionally refer to a job match between a worker and a firm located at a distance $x$ one from another as a type $x$ job.

We first write the equations describing the value of a firm holding an open vacancy: ${ }^{7}$

$$
r V=\dot{V}-c+q(\theta)\left[2 \int_{0}^{\bar{x}}(J(x)-V) d x\right] .
$$

\footnotetext{
${ }^{7}$ We drop time indices for convenience when this causes no confusion.
} 
where $V$ is the value of a vacancy, $J(x)$ is the asset value of a filled vacancy with a type $x$ job. Observe that $V$ does not depend on $x$, since firms cannot sort agents by locations. $q(\theta)$ represents the probability for a firm with an open vacancy to be matched with a randomly drawn worker. The match will be acceptable only if the worker interviewed turns out to be located on a point along the arc of length $2 \bar{x}$ centered on the firm's location, otherwise it will be rejected. Therefore, the last term on the right hand-side of (3) represents the expected capital gain to a firm which posts a vacancy from filling the position. We assume that entry in vacancy creation is free. Since the value of idle firms is zero, entry will drive the value of all vacancies down to zero. Thus, in equilibrium:

$$
V=0 .
$$

We then define the value of a firm which has a filled job of type $x$ :

$$
(r+d) J(x)=\dot{J}(x)+\eta(x)-w(x)+d V,
$$

where $w(x)$ is the wage received by the worker.

Next, consider the workers' decisions. First, let $W(x)$ be the asset value of a type $x$ job. This is determined by the following equation.

$$
(r+d) W(x)=w(x)+\dot{W}(x)+d U,
$$

where $U$ denotes the value of being unemployed. The value of unemployment depends, among other things, on the proportion of interviews which give rise to jobs. When a worker interviews with a firm, he will get the job only if the firm is located in an arc of length $2 \bar{x}$ centered on his location. Hence:

$$
r U=\dot{U}+b+\theta q(\theta)\left[2 \int_{0}^{\bar{x}}(W(x)-U) d x\right]
$$

A successful acceptable job match generates a rent. We assume that if this rent is positive it is shared between the firm and the worker, according to the Nash bargaining solution. The total surplus is given by $S(x)=(J(x)-V+W(x)-U)$, and the Nash solution implies that:

$$
W(x)-U=\frac{\beta}{1-\beta}(J(x)-V) \quad \text { if } x \leq \bar{x}
$$

where $\beta$ is a parameter representing the bargaining power of the workers, and we remind that $V=0$ due to free entry. Note that (8) ensures that if a worker finds 
it acceptable a particular match acceptable, so will do the firm and viceversa (i.e. $J(x) \geq V \Leftrightarrow W(x) \geq U)$.

Using the set of equations from (3) to (8), we can obtain an expression for the wage rate paid to a worker holding a job of type $x$ as a function of his productivity, tightness of the labor market, $\theta$, and parameters:

$$
w(x)=\beta(\eta(x)+c \theta)+(1-\beta) b \quad \text { if } x \leq \bar{x}
$$

Since matches which do not generate a positive surplus $(x>\bar{x})$ will not be acceptable, equations (3)-(9) provide a sufficient characterization for a stationary environment. However, we will want to analyze the response of the economy to unexpected parameter changes. In this case, it is possible that rents generated by some preexisting jobs (which were positive before the shock) turn negative after the shock. When this is the case, it is not plausible to maintain that all wages of existing jobs are determined by (9), namely that workers and firms share both rents and losses according to the Nash rule. This would have the unrealistic implication that some workers earn a wage which yields them lower utility than if they were unemployed. These workers would rather quit their job, unless one assumes that this is prevented by some 'slavery' contract. To avoid this unappealing implication, we could assume that separation is partially endogenous, i.e. as soon as a job ceases to be profitable it can be destroyed at no cost. The shortcoming of this assumption would be that aggregate shocks could generate discontinuous jumps in the mass of unemployed in the economy. Apart from originating some technical complications, this does not seem a realistic feature, either. We will instead assume, therefore, that if the surplus generated by a job turns negative, the firm must bear the entire loss, and pay the worker a salary granting him the same utility which he would perceive if he were unemployed. Formally:

$$
w(x)=\max [r U, \beta(\eta(x)+c \theta)+(1-\beta) b]
$$

Note that (10) is consistent with (9). In particular, the worker receives the reservation wage when $x>\bar{x}$, namely in the range in which $J(x)<0$. This assumption will not affect any of the main results of the paper, which would remain unchanged if we assumed free disposal of unproductive jobs. The only important difference would concern the characterization of transitional dynamics. 


\section{Equilibrium.}

In this section we will characterize the equilibrium of the model. First, we will derive the unique stationary equilibrium pair $\left(\bar{x}^{e}, \theta^{e}\right)$ from the set of equations (3)-(9), by setting $\dot{V}=\dot{J}=\dot{W}=\dot{U}=0$ (subsection 3.1 ). Then, we will study the comparative statics of a change in the unemployment benefit (subsection 3.2). Finally, we will characterize the equilibrium dynamics of output and unemployment (subsection 3.3).

\subsection{Allocation of talents and vacancy creation .}

We will proceed in two steps. We will first find the locus of pairs $(\bar{x}, \theta)$ which are consistent with the optimal 'allocation of talents' (comparative advantage) choice of workers and firms. Then, we will find the locus of pairs of pairs $(\bar{x}, \theta)$ which are consistent with free-entry in vacancy creation. These two condition will jointly determine the equilibrium pair $\left(\bar{x}^{e}, \theta^{e}\right)$, whose existence and uniqueness will be proved.

We recall that by the Nash rule a firm and a worker always agree, upon interview, at whether the match between them is profitable. Formally, a job is formed whenever $J(x)>0$, which implies, by (8), that $W(x)>U$. Two alternative cases are possible. In the first, $J(x)>0$ for all $x$, and all matches are regarded as acceptable. In the second, there exists a threshold job type, $\bar{x}$, such that $J(\bar{x})=0$ (hence, $W(\bar{x})=U)$.

Before stating the result formally (Lemma 1), we define $\bar{\eta}(\bar{x}) \equiv \frac{\int_{0}^{\bar{x}} \eta(x) d x}{\bar{x}}$, i.e. $\bar{\eta}$ is the average productivity of acceptable matches.

Lemma 1 (Allocation of talents.) A necessary condition for an equilibrium is:

$$
(\eta(\bar{x})-b)-\frac{2 \beta \bar{x} \theta q(\theta)}{r+d+2 \beta \bar{x} \theta q(\theta)}(\ddot{\eta}(\bar{x})-b) \geq 0
$$

or, equivalently:

$$
(1-\beta)(\eta(\bar{x})-b)-\beta c \theta \geq 0
$$

Both (11) and (12) hold with equality if $\bar{x}<\frac{1}{2}$.

The proofs of all Lemmas are in the Appendix. Equation (11) has the intuitive economic interpretation of a comparative advantage condition. The search cut-off is such that the value of forming a type $\bar{x} j o b$ is equal to the value of waiting, i.e. the present discounted expected value of a future match (except for the case in which $\bar{x}=\frac{1}{2}$, in whose case waiting is always a dominated option). Differently from (11), 
(12) is obtained by also using the equilibrium condition for vacancy creation, (3) see appendix -, and its interpretation is therefore less transparent. However, (12) is more tractable and will be useful to characterize the general equilibrium solution of the model through a geometrical argument.

The other condition which is used to find the equilibrium yields the set of pairs $(\theta, \bar{x})$ which are consistent with the free entry condition in vacancy creation $(V=0)$.

Lemma 2 (Vacancy creation.) A necessary condition for an equilibrium is:

$$
-c+\frac{(1-\beta) 2 \bar{x} q(\theta)}{r+d+\beta 2 \bar{x} \theta q(\theta)}(\bar{\eta}(\bar{x})-b)=0 .
$$

The equilibrium condition (13) states that the cost of keeping an open vacancy to a firm has to be equal to the expected profit from filling the position.

It will be convenient to define the two following functions:

$$
\begin{gathered}
\ell^{p}(\theta, \bar{x}) \equiv(1-\beta)(\eta(\bar{x})-b)-\beta c \theta \\
\ell^{v}(\theta, \bar{x}) \equiv-c(r+d+\beta 2 \bar{x} \theta q(\theta))+(1-\beta) 2 \bar{x} q(\theta)(\bar{\eta}(\bar{x})-b),
\end{gathered}
$$

and rewrite equations (12) and (13) - when they hold both with equality - as $\ell^{p}(\theta, \bar{x})=0$ and $\ell^{\nu}(\theta, \bar{x})=0$, respectively. These two equations are represented geometrically by the skill allocation and vacancy creation schedule in figure 1, respectively.

Consider, first, the skill allocation schedule. The more frequently matches occur (high $\theta$ ), the more easily unemployed workers expect to face better job opportunities in the future, and the less eager they are to accept low productivity jobs which pay low wages (small $\vec{x}$ ). Thus, in tight labor markets, people seeking employment tend to be highly choosy, and only accept very 'suitable' jobs. Since $\eta(x)$ is a continuous and bounded function, the range of values of $\theta$ which is consistent with (12) is bounded, too. Provided that $\eta_{l}>b$, there exists $\theta^{*}>0$ such that $\ell^{p}\left(\theta^{*}, \frac{1}{2}\right)=0$, namely there exists a sufficiently low matching rate, such that all jobs, even those implying the largest mismatch, are regarded as acceptable. In particular, from (12), it follows that $\theta^{*}=\frac{1-\beta}{\beta c} \eta_{l}$. The particular skill allocation schedule drawn in figure 1 corresponds to the piece-wise linear productivity function of equation (1). In this case the schedule becomes vertical at $\theta^{*}$ in correspondence of values of $\bar{x}$ exceeding $\frac{1}{\gamma}$, since all 'bad' jobs located at a distance larger than $\frac{1}{\gamma}$ have the same low productivity. 


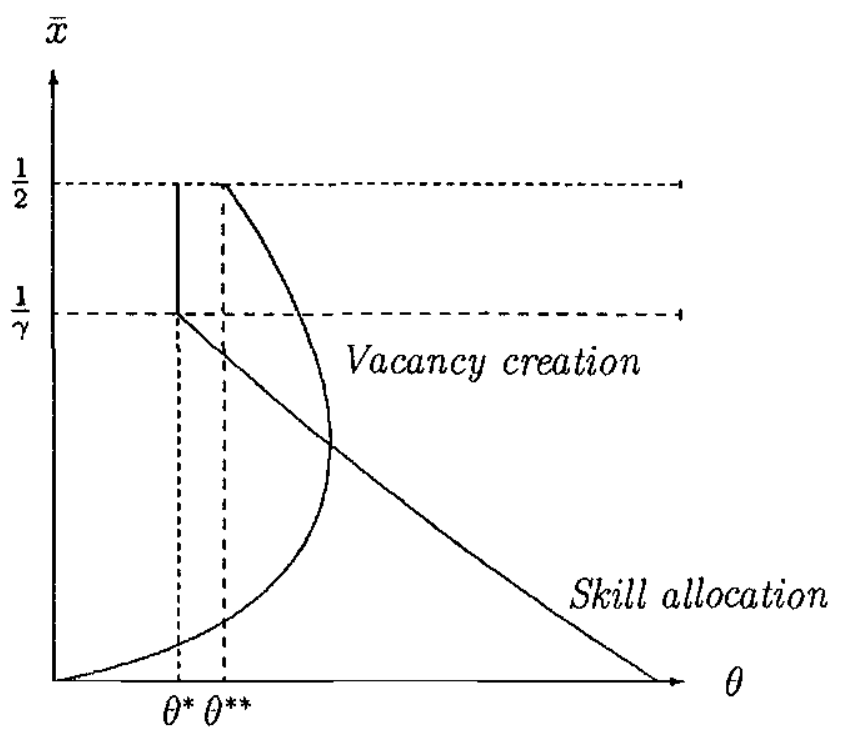

Figure 1. Interior solution.

Thus, workers accept jobs along the whole circle (i.e. choose $\bar{x}=\frac{1}{2}$ ) if $\theta<\theta^{*}$, and set the cut-off distance below $\frac{1}{\gamma}$ if $\theta>\theta^{*}$.

Consider, next, the vacancy creation schedule. Determining the slope of this schedule is less immediate; although it is easy to see that $\ell_{1}^{v}(\theta, \bar{x})<0$, the partial derivative $\ell_{2}^{v}(\theta, \bar{x})$ has in fact an ambiguous sign. We will prove below (proof of Proposition 1) that this schedule is either 'backward bending' as in figure 1, or monotonously increasing as in figure 2. The intuitive reason for the ambiguous slope of the schedule is that an increase of $\vec{x}$ has two opposite effects on the expected return of a vacancy. On the one hand, it reduces the waiting time of firms holding a vacancy before they can fill the position. On the other hand, it deteriorates the expected quality of the worker which will be hired. Parallel to the definition of $\theta^{*}$ provided above, we can define $\theta^{* *}$ as the matching rate such that $\ell^{v}\left(\theta^{* *}, \frac{1}{2}\right)=0$, namely $\theta^{* *}$ is the matching rate which is consistent with equilibrium in vacancy creation when all interviews give rise to a job.

The following proposition establishes the properties of the steady-state equilibrium of the model.

Proposition 1 Assume $\eta_{u}>b$. Then:

a) There exists a (generically) unique stationary equilibrium pair $\left(x^{e}, \theta^{e}\right)$. 




Figure 2. Corner solution.

b) (i) If $\theta^{*}<\theta^{* *}$, then $0<\bar{x}^{e}<\frac{1}{2}$, and the equilibrium pair $\left(x^{e}, \theta^{e}\right)$ is as determined by (12) and (13); (ii) if $\theta^{*} \geq \theta^{* *}$, then $\bar{x}^{e}=\frac{1}{2}$ and $\theta^{e}=\theta^{* *}$.

Proof. We prove the Proposition through simple geometrical arguments.

To prove existence, we will first establish that either the Vacancy creation schedule $(V C)$ lies entirely to the left of the Skill allocation schedule $(S A)$, or the two schedules cross; we then establish that in both cases an equilbrium exists. To rule out that $V C$ is entirely to the right of $S A$, observe that from (12) it follows that $V C$ intersects the horizontal axis in correspondence of $\theta=\frac{(1-\beta)}{\beta c}\left(\eta_{u}-b\right)>0$, while from (13) $S A$ intersects the horizontal axis in correspondence of the origin. Hence, at $\bar{x}=0 V C$ is always to the left of $S A$. Assume that $V C$ is entirely to the left of $S A$. Then, it can be checked that the solution $\left(\theta^{e}=\theta^{* *}, \bar{x}^{e}=\frac{1}{2}\right)$ satisfies the conditions of Lemmas 1 and 2 (with (11)-(12) holding with strict inequality) and is, therefore, an equilibrium. Assume, instead, that $V C$ and $S A$ intersect. Then, it is immediate to show that any intersection point identifies an equilibrium.

To prove uniqueness, we show that the two schedules can cross at most once. We start from recalling that $\ell_{1}^{v}(\theta, \bar{x})<0$. Then, standard differentiation shows that $V C$ is positively (negatively) sloped if and only if $\ell_{2}^{v}(\theta, \bar{x})>(<) 0$. Next, observe that $\ell_{2}^{v}(\theta, \bar{x})=(1-\beta)(\eta(\bar{x})-b)-\beta c \theta$ (to obtain this result, we use the fact that from the definition of $\bar{\eta}(\bar{x})$ it follows that $\left.\bar{\eta}^{\prime}(\bar{x}) \bar{x}=\eta(\bar{x})-\bar{\eta}(\bar{x})\right)$. Hence, 


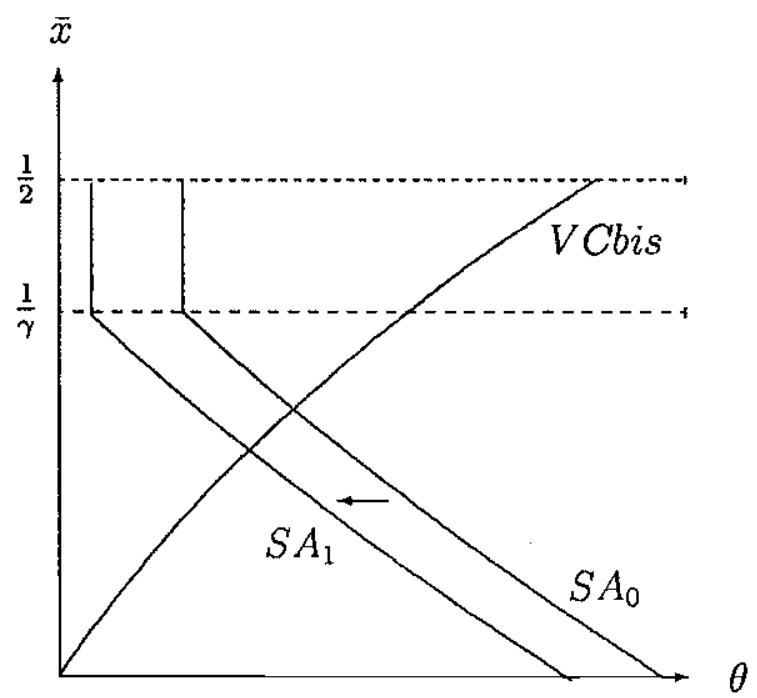

Figure 3. Effect of an increase of $b$.

$\operatorname{sign}\left[\ell_{2}^{\nu}(\theta, \bar{x})\right]=\operatorname{sign}[(1-\beta)(\eta(\bar{x})-b)-\beta c \theta]=\operatorname{sign}\left[\ell^{p}(\theta, \bar{x})\right]$. This implies that $V C$ is positively sloped when it lies to the left of $S A$ (since in this region $\ell^{p}(\theta, \bar{x})>0$ ), negatively sloped when it lies to the right of $S A$ (since in this region $\ell^{\rho}(\theta, \bar{x})<0$ ) and vertical when the two schedules intersect (since $\ell^{p}(\theta, \bar{x})=0$ along $S A$ ). Since $S A$ is everywhere (weakly) negatively sloped, the two schedules can cross at most once. It is also straightforward to check that when the two schedule cross, no corner solution is an equilibrium. Hence, the equilibrium is unique.

Finally, the inspection of figures 1 and 2 immediately reveals that the equilibrium is interior if and only if $\theta^{*}<\theta^{* *}$ and is a corner solution if and only if $\theta^{*} \geq \theta^{* *}$. Hence, part $b$ of the Proposition. QED.

Proposition 1 rules out the possibility of multiple equilibria. If the two schedules cross, then we have the unique interior equilibrium described by figure 1 . If they do not cross, then the vacancy creation schedule is everywhere positively sloped, and we have a corner solution, like in figure 2. The solution collapses in this case to that of a standard model without heterogeneity where all interviews give rise to a job. Corner solutions occur when the productivity gap between good and bad matches is very small, or when search frictions are very pronounced, and the frequency of interviews is very low. 


\subsection{Comparative statics: changing the level of unemploy- ment benefits.}

We can now discuss an important result of comparative statics: the effect of an increase of unemployment benefits. When $b$ increases, both curves in figures 1 and 2 would shift to the left, and the geometrical analysis followed so far is inconclusive. It can be shown, however, that when $b$ goes up both the search cut-off level and the tightness of the labor market fall. To this aim, we first rearrange (11) as follows:

$$
(\bar{\eta}(\bar{x})-b)=\frac{(r+d+2 \beta \bar{x} \theta q(\theta))(\bar{\eta}(\bar{x})-\eta(\bar{x}))}{(r+d)} .
$$

Next, replacing the left hand-side of (14) into (13), we obtain:

$$
\frac{1}{q(\theta)}-\left[\frac{(1-\beta) 2 \bar{x}(\bar{\eta}(\bar{x})-\eta(\bar{x}))}{(r+d) c}\right]=0
$$

Equations (12) and (15) provide an alternative characterization of the equilibrium, when this is interior. The advantage of this formulation is that only (12) depends on $b$, and this facilitates the geometrical analysis of the comparative statics. Equation (15) defines a positively sloped locus - labeled in figure 3 as $V C b i s$ - in the plane $(\theta, \bar{x})$. This can be shown by observing that $\frac{1}{q(\theta)}$ is an increasing function of $\theta$, while $\frac{d}{d \bar{x}}[(\bar{\eta}(\bar{x})-\eta(\bar{x})) \bar{x}]=-\bar{x} \eta^{\prime}(\bar{x})>0$ and using standard differentiation. When $b$ grows, the skill allocation schedule shifts to the left, and the equilibrium has a lower search cut-off as well as a less tight a labor market. The more generous insurance, the lower mismatch and the higher productivity per worker in equilibrium. But, at the same time, unemployment insurance depresses job creation and employment.

\subsection{Dynamics of production and unemployment.}

We have characterized so far the steady-state equilibrium search cut-off, $\bar{x}^{e}$, and the vacancy to unemployment ratio, $\theta^{e}$. Since all Bellman equations of section 2.2 are independent of any state variable (unemployment and output, in particular), $\bar{x}^{e}$ and $\theta^{e}$ exhibit no transitional dynamics. In particular, if the value of some parameter changes unexpectedly, both the number of vacancies at any location and the search cut-off level jump to their new stationary equilibrium level.

Unemployment and (gross) production are instead predetermined and exhibit non-trivial transitional dynamics. In this section, we fully characterize these dy- 
namics. Define gross production at time $t$ as $y_{t}{ }^{8}$ The equations describing the dynamics of these two variables are, respectively:

$$
\dot{u}_{t}=d\left(1-u_{t}\right)-2 \bar{x}^{e} \theta^{e} q\left(\theta^{e}\right) u_{t}
$$

and:

$$
\dot{y}_{t}=\bar{\eta}\left(\bar{x}^{e}\right) 2 \bar{x}^{e} \theta^{e} q\left(\theta^{e}\right) u_{t}-d y_{t},
$$

given initial conditions $u_{0}, y_{0}$. Equation (16) has a standard interpretation: the flow into unemployment is given by the exogenous separations, $d\left(1-u_{t}\right)$, while the flow out of unemployment is given by the probability that an unemployed worker finds an acceptable match, $2 \bar{x}^{e} \theta^{e} q\left(\theta^{e}\right)$, times the mass of unemployed at time $t$. To understand (17), observe that the average productivity of new jobs generally differs from that of the flow of jobs which are terminated. In particular, the average productivity of the workers which are employed at time $t$ is a predetermined variable which depends on past decisions of firms and workers. Let us denote this predetermined variable by $\pi_{t}$. Thus the flow of output which is lost at time $t$ due to job termination is $d \pi_{t}\left(1-u_{t}\right)=d y_{t}$ (note that gross production, also predetermined, is equal to $\pi_{t}\left(1-u_{t}\right)$ ). The average productivity of newly hired workers is not predetermined, though. New jobs are uniformly distributed on the interval $\left[0, \bar{x}^{e}\right]$ and the average product which they generate is $\bar{\eta}\left(\bar{x}^{e}\right)$. The output flow which originates from new jobs is then equal to the average productivity of new jobs, $\bar{\eta}(\bar{x})$, times the new successful matches, $\left.2 \bar{x}^{e} \theta^{e} q\left(\theta^{e}\right) u_{t}\right)$. Hence, equation (17) follows.

The pair of equations (16)-(17) define a system of linear differential equations. Standard methods establish that the solutions is:

$$
\begin{gathered}
u_{t}=u^{*}+\left(u_{0}-u^{*}\right) e^{-\left(2 \bar{x}^{e} \theta^{e} q\left(\theta^{e}\right)+d\right) t} \\
y_{t}=y^{*}+\left[\left(y_{0}-y^{*}\right)+\bar{\eta}\left(\bar{x}^{e}\right)\left(u_{0}-u^{*}\right)\right] e^{-d t}-\bar{\eta}\left(\bar{x}^{e}\right)\left(u_{0}-u^{*}\right) e^{-\left(2 \bar{x}^{e} \theta^{e} q\left(\theta^{e}\right)+d\right) t}
\end{gathered}
$$

where

$$
u^{*}=\frac{d}{d+2 \bar{x}^{e} \theta^{e} q\left(\theta^{e}\right)}
$$

and

$$
y^{*}=\bar{\eta}\left(\bar{x}^{e}\right) \frac{2 \bar{x}^{e} \theta^{e} q\left(\theta^{e}\right)}{d+2 \bar{x}^{e} \theta^{e} q\left(\theta^{e}\right)}
$$

\footnotetext{
${ }^{8}$ We define as net production the production flow generated by firms holding a filled position minus the hiring expenditure flow suffered by firms holding a vacant position. Gross production is equal to net production plus hiring expenditure.
} 
are the steady-state equilibrium unemployment and gross production levels. It is easy to check that this system of differential equations is globally stable, thus the economy converges to $y^{*}, u^{*}$ starting from any pair of initial conditions $u_{0}, y_{0}$.

To determine net production, finally, observe that the aggregate hiring expenditure in the economy is given by $c v_{t}=c \theta u_{t}$. Thus, denoting net production as $z=y_{t}-c \theta u_{t}$, we have:

$z_{t}=z^{*}+\left[\left(y_{0}-y^{*}\right)-\bar{\eta}\left(\bar{x}^{e}\right)\left(u_{0}-u^{*}\right)\right] e^{-d t}-\left(\bar{\eta}\left(\bar{x}^{e}\right)+c \theta^{e}\right)\left(u_{0}-u^{*}\right) e^{-\left(2 \bar{x}^{e} \theta^{e} q\left(\theta^{e}\right)+d\right) t}$

where $z^{*}=y^{*}-c \theta^{e} u^{*}$. Equations (18), (19) and (22) together with Proposition 1 provide a complete characterization of the decentralized equilibrium, given initial conditions $u_{0}$ and $y_{0}$.

\section{Welfare analysis.}

In this section, we will first contrast the decentralized equilibrium with the allocation chosen by a social planner subject to the same matching frictions as the market economy, and then analyze how gairs and losses from policy changes are distributed among the different social groups. For simplicity, throughout the rest of the paper we will parameterize the matching technology by the standard isoelastic function, $q(\theta)=\theta^{-\alpha}$.

\subsection{Efficient allocation of workers to jobs.}

Consider the following planning problem. We assume that the planner is only subject to the search frictions and can costlessly redistribute income among agents (or, alternatively, the planner has no egalitarian concern). Since non-distortionary redistribution is feasible, we will assume without any loss of generality that the unemployed receive no benefits, and only perceive the value of pure leisure which will be denoted by $b_{l}$. The planner maximizes the present discounted value of the output stream plus leisure, given initial conditions. The state variables are the unemployment $\left(u_{t}\right)$ and gross production $\left(y_{t}\right)$ level. The optimal allocation is given by the solution of the following program:

$$
\max _{\left\{u_{t}, \bar{x}_{t}, \theta_{t}\right\}} \int_{0}^{\infty} e^{-r t}\left(z_{t}+b_{l} u_{t}\right) d t=\int_{0}^{\infty} e^{-r t}\left(y_{t}+b_{l} u_{t}-c \theta_{t} u_{t}\right) d t
$$


subject to:

$$
\begin{aligned}
& \dot{u}_{t}=d\left(1-u_{t}\right)-2 \bar{x}_{t} \theta_{t}^{1-\alpha} u_{t} ; \\
& \dot{y}_{t}=\bar{\eta}\left(\bar{x}_{t}\right) 2 \bar{x}_{t} \theta_{t}^{1-\alpha} u_{t}-d y_{t} ;
\end{aligned}
$$

the feasibility constraints that $u_{t} \in[0,1]$ and $\bar{x}_{t} \in\left[0, \frac{1}{2}\right]$ and a pair of initial condition $u_{0}, y_{0}$. The corresponding present value Hamiltonian is:

$$
\begin{gathered}
H\left(u_{t}, y_{t}, \bar{x}_{t}, \theta_{t}, \mu_{t}, \gamma_{t}\right)=y_{t}+b_{l} u_{t}-c \theta_{t} u_{t}- \\
\mu_{t}\left[d\left(1-u_{t}\right)-2 \bar{x}_{t} \theta_{t}^{1-\alpha} u_{t}\right]+\gamma_{t}\left(\bar{\eta}\left(\bar{x}_{t}\right) 2 \bar{x}_{t} \theta_{t}^{1-\alpha} u_{t}-d y_{t}\right)
\end{gathered}
$$

where $-\mu$ and $\gamma$ are a pair of costate variables. The first order conditions for an interior solution are:

$$
\begin{gathered}
\mu_{t}+\gamma_{t}\left(\bar{\eta}^{\prime}\left(\bar{x}_{t}\right) \bar{x}_{t}+\bar{\eta}\left(\bar{x}_{t}\right)\right)=0 \\
-c+2 \mu_{t}(1-\alpha) \bar{x} \theta_{t}^{-\alpha}+2 \gamma_{t}(1-\alpha) \bar{\eta}\left(\bar{x}_{t}\right) \bar{x}_{t} \theta_{t}^{-\alpha}=0 \\
b_{l}-c \theta_{t}+\mu_{t}\left[d+2 \bar{x} \theta^{1-\alpha}\right]+2 \gamma_{t} \bar{\eta}\left(\bar{x}_{t}\right) \bar{x}_{t} \theta_{t}^{1-\alpha}=-r \mu_{t}+\dot{\mu}_{t} \\
1-d \gamma_{t}=r \gamma_{t}-\dot{\gamma}_{t}
\end{gathered}
$$

and the transversality conditions are given by $\lim _{t \rightarrow \infty} e^{-r t} \mu_{t} u_{t}=0$ and $\lim _{t \rightarrow \infty} e^{-r t} \gamma_{t} y_{t}=$ 0 . Observe that the F.O.C.'s (27) to (30) are independent of the state variables $u_{t}, y_{t}$. Hence, the four equations determine a stationary solution $\left(\bar{x}^{p}, \theta^{p}, \mu^{p}, \gamma^{p}\right)$ which satisfies the transversality conditions. In particular, using (27) and (30), we obtain: $\gamma^{p}=\frac{1}{r+d}$ and $\mu^{p}=-\frac{\bar{\eta}^{\prime}\left(\bar{x}_{t}\right) \bar{x}_{t}+\bar{\eta}_{\left(\bar{x}_{t}\right)}}{r+d}$. Substituting $\gamma^{p}$ and $\mu^{p}$ into (28) and (29), and rearranging terms, yields :

$$
\begin{gathered}
\left(\eta\left(\bar{x}^{p}\right)-b_{l}\right)-\frac{2 \alpha \bar{x}^{p} \theta^{p}(1-\alpha)}{r+d+2 \alpha \bar{x}^{p} \theta^{p}(1-\alpha)}\left(\bar{\eta}\left(\bar{x}^{p}\right)-b\right)=0 \\
-c+\frac{(1-\alpha) 2 \bar{x}^{p} \theta^{p}(-\alpha)}{r+d+\alpha 2 \bar{x}^{p} \theta^{p(1-\alpha)}}\left(\bar{\eta}\left(\bar{x}^{p}\right)-b_{l}\right)=0
\end{gathered}
$$

Equations (31) and (32) determine the optimal pair $\left(\bar{x}^{p}, \theta^{p}\right)$. This solution can be contrasted with the equilibrium conditions of the decentralized economy, given by (11) and (13), recalling that $q(\theta)=0^{-\alpha}$. First, compare (32) with (13), namely the equilibrium and optimality condition for vacancy creation. The two equations are identical if and only if $\alpha=\beta$. This is consistent with the well-known result that the equilibrium rate of job creation is inefficient when there are search frictions in the labor market except for the non-generic case when the elasticity of the matching 
function is equal to the bargaining power of workers (Hosios, 1989; Pissarides, 1990). Next, compare (31) with (11), namely the equilibrium and optimality condition which determine the search cut-off level chosen by workers (and firms). These two equations, too, are identical if and only if $\alpha=\beta$. In summary, we generalize the Hosios-Pissarides welfare theorem to encompass skill-mismatch.

Proposition 2 The competitive search-matching equilibrium is efficient-in terms of both job creation and assignments- if and only if $\alpha=\beta$.

Proposition 2 (proof in the text) establishes that in a decentralized equilibrium mismatch is generically suboptimal - either too large or too small - but when the Hosios-Pissarides condition is satisfied workers are assigned to jobs efficiently. The following corollary, whose proof follows immediately from the analysis above, states the direction of the bias.

Corollary 1 Given $\theta$, if $\beta>\alpha[\beta<\alpha]$ there is an inefficient underassignment [overassignment] of workers to jobs.

Conditional on a given rate of vacancy creation (i.e. for fixed $\theta$ ), when workers' bargaining power is relatively large $(\beta>\alpha)$, agents are too picky, and turn down jobs which would increase the present discounted value of output. Viceversa, when $\beta<\alpha$ then too many interviews give rise to new jobs and there is excess mismatch. In this case, a positive level of unemployment benefits will make workers more selective and improve efficiency.

\subsection{Related efficiency results in mismatch models.}

The findings of Proposition 2 and its Corollary, parallel and generalize the recent efficiency results of Mortensen (1996a), who analyzes the Mortensen and Pissarides (1994) model of ex-post heterogeneity. He shows that the efficient outcome, in terms of both employment creation and ex-post assignment of workers to jobs, is efficient if and only if the Hosios-Pissarides elasticity condition is satisfied. Our results show that our model with ex-ante heterogeneity shares the same efficiency properties.

This result contrasts with some earlier findings in the literature on mismatch showing the inefficieny in the allocation of workers to jobs in models of exogeneous job creation. For example, Diamond (1981) shows that the matching between heterogeneous workers and firms is in general inefficient, but his result relies on the 
assumption of increasing returns to scale to the matching technology, while here we assume a standard constant returns to scale matching technology.

Sattinger (1995), instead, constructs a model with a finite number of types of job and workers and an equal number of jobs and firms and shows that in the presence of ex-ante heterogeneity of workers and firms the decentralized mechanism of assignment of workers to jobs tend to be inefficient. In particular, the set of matches which are formed according to the reservation wages and profits set by workers and firms is generically different from that which a planner would choose, and multiple equilibria are possible. Two important features explain the difference in the results. First, in Sattinger's model, by construction, there are as many unemployed as there are vacancies, whereas in ours the 'tightness' of the market is endogenously determined. Second, in our symmetric model workers, although heterogeneous, are not 'ranked', namely given two workers, it is never the case that one of them is uniformly more productive for all firms or, at least, for a majority of firms. On the one hand, symmetry is crucial to rule out multiple equilibria and generic inefficiencies of the type identified by Sattinger. On the other hand, while this symmetry would be sufficient to get efficiency in Sattinger's model, in our model - due to the endogeneity of job creation - the elasticity condition is also necessary. In the Appendix, we consider a symmetric version of Sattinger's model which is equivalent to a particular case of our model with costless job creation $(c=0)$ and show that in this case the decentralized equilibrium is always efficient. However, when job creation is costly $(c>0)$, the assignment becomes inefficient unless the 'elasticity condition' is satisfied.

In summary, this section generalizes the standard welfare theorem of search equilibria to economies with endogenous job mismatches, provided that job mismatch is not associated with other forms of market failure.

\subsection{Unemployment benefits and income distribution.}

The analysis carried on so far has ignored distributional issues by assuming that either the planner has access to lump sum taxation or does not care about equality. When these assumptions are relaxed, the presence of heterogeneity has important normative implications. The rest of this section will deal with distributional issues, and will analyze who loose and who gains from changing the system of unemployment benefits.

The analysis of section 4.1 shows that unemployment benefits have ambiguous 
effects on global efficiency. However, changing the degree of insurance has also distributional implications, and will in general benefit some social groups and harm others. With respect to this point, it is important to recall that we have assumed that firms are owned by a class of pure rentiers ('capitalist') who do not work. This is a stylized and extreme form of heterogeneity in the composition of wealth across social groups: some agents hold only human wealth, while other agents hold only non-human assets. Although per se not realistic, this is a stylized approximation of a situation in which portfolio composition is to some extent socially polarized, and workers' wealth consists mainly of human assets. A further simplifying assumption which we will introduce is that only the workers have to pay for the unemployment insurance system. As it will be easily seen, if firms were also required to pay for the provision (e.g. through a corporate tax), all our results would be strengthened.

Consider an economy in which the unemployed receive a provision equal to $b_{0}$. Unemployment and output are at the corresponding steady-state, $u_{0}\left(b_{0}\right), y_{0}\left(b_{0}\right)$. Given steady state, filled jobs are uniformly distributed over the interval $\left[0, \bar{x}_{0}^{e}\left(b_{0}\right)\right]$. We want to assess the distribution of costs and benefits from changing the level of unemployment benefits to $b$. To begin with, we will ignore the cost of financing the provision (as if unemployment benefits were granted financial aid). For simplicity, we will obtain the results for the case in which $\eta^{\prime}(x)<0$ for all $x$. The extension to the case in which $\eta(x)$ is weakly monotonous is trivial.

Lemma 3 Let $b>b_{0}$ and $0.5 \geq \bar{x}^{e}\left(b_{0}\right)>\bar{x}^{e}(b)$. Then:

1. For all $x \leq \bar{x}^{e}\left(b_{0}\right)$, we have $J(x, b)<J\left(x, b_{0}\right), W(x, b)>W\left(x, b_{0}\right), U(b)>$ $U\left(b_{0}\right)$.

2. For all $x \leq \bar{x}_{0}^{e}\left(b_{0}\right), U(b)-U\left(b_{0}\right) \geq W(x, b)-W\left(x, b_{0}\right)$.

3. Let $x>x^{\prime}$. Then: $W(x, b)-W\left(x, b_{0}\right) \geq W\left(x^{\prime}, b\right)-W\left(x^{\prime}, b_{0}\right)$. In particular:

a) If both $x, x^{\prime} \in\left[0, \bar{x}^{e}(b)\right]$, then $W(x, b)-W\left(x, b_{0}\right)=W\left(x^{\prime}, b\right)-W\left(x^{\prime}, b_{0}\right)$;

b) If $x \in\left[\bar{x}^{e}(b), \bar{x}_{0}^{e}\left(b_{0}\right)\right]$ and $x^{\prime} \in\left[0, \bar{x}_{0}^{e}\left(b_{0}\right)\right]$, then $W(x, b)-W\left(x, b_{0}\right)>$ $W\left(x^{\prime}, b\right)-W\left(x^{\prime}, b_{0}\right)$.

The Lemma establishes the redistributive effects of a change in benefit provision. A raise of $b$ increases the reservation wage of workers and the value of human assets of all workers (both employed and unemployed), while decreases the value of firms 
(part 1). However, the effects are not symmetric. The unemployed workers perceive the largest gains (part 2). Furthermore, some richer employed workers benefit less than some poorer co-workers (part 9). To understand why, observe that a group of relatively poor workers, namely those whose mismatch level ranges in the interval $x \in$ $\left[\bar{x}^{e}(b), \bar{x}_{0}^{e}\left(b_{0}\right)\right]$, are employed in jobs which turn non-profitable when the benefits go up to $b$. By assumption, these workers are entitled to earn more than what the Nash rule would grant to them, and cannot be worse off than the unemployed who perceive the benefit $b$ (see equation (10)). These poor workers receive a premium over the wage increase which accrues to their richer, better-matched colleagues (part $3 b$ ). The welfare gains of all workers belonging to this richer group are instead the same, irrespective of $x$ (part $3 a$ ). We should stress here that part $3 \mathrm{~b}$ of the Proposition does not descend from the assumption that firms cannot dismiss workers when the match is no longer productive. If we assumed that in all circumstances workers receive the wage corresponding to the Nash solution, but bad paid workers can quit their job, this Lemma would be unchanged. Instead, it is crucial to rule out 'slavery', i.e. workers cannot be forced to work for less than the reservation utility of getting unemployed.

Next, we consider the cost of financing the system. Assume that the system is financed through lump sum taxes levied on all workers (both employed and unemployed), and that at each $t$ all workers (both employed and unemployed) have to pay a tax equal to $\tau=b u_{t}$. Let $T$ denote the asset value of 'being a tax-payer' of a country in which the unemployed receive the gross benefit $b$. Then:

$$
T\left(b, u_{0}\right)=-b \int_{0}^{\infty} e^{-r t} u_{\iota}\left(b, u_{0}\right) d t .
$$

$T\left(b, u_{0}\right)$ is a decreasing functions of $b$, since the higher $b$ the larger the fiscal burden to finance the provision.

We will now compute the net welfare change of each type of worker. The net gain for a worker of a give type is given by the difference between the change in the labor income and the change in the tax burden. Denote, then, by $N W$ and $N U$ the net wealth of employed and unemployed workers, respectively. Formally, we have $N W\left(x, b, u_{0}\right) \equiv W(x, b)-T\left(b, u_{0}\right)$ and $N U\left(b, u_{0}\right) \equiv U(b)-T\left(b, u_{0}\right)$. Recall here that $T\left(b, u_{0}\right)$ is the same for all workers, while the labor income gain depends on the initial income (type) of the worker (Lemma 3). This observation immediately leads to the following Proposition.

Proposition 3 Let $b>b_{0}$. Assume that, at $t=0, u_{0}=u^{*}\left(b_{0}\right)$ and $y_{0}=y^{*}\left(b_{0}\right)$ 


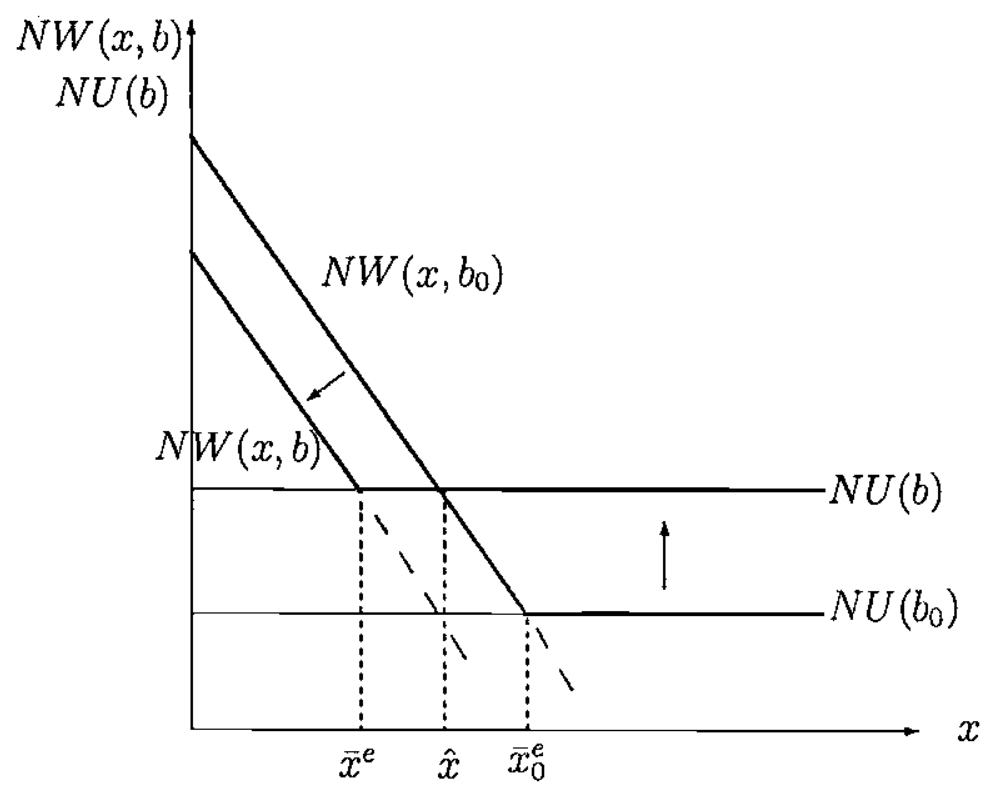

Figure 4. Proposition 3, part 3.

(where starred letters denote steady-states). Then, we have one of the following:

1. $N U\left(b, u_{0}\right)>N U\left(b_{0}, u_{0}\right)$ and, for all $x, N W\left(x, b, u_{0}\right) \geq N W\left(x, b_{0}, u_{0}\right)$ (all workers unanimously prefer $b$ to $\left.b_{0}\right)$.

2. $N U\left(b, u_{0}\right) \leq N U\left(b_{0}, u_{0}\right)$ and, for all $x, N W\left(x, b, u_{0}\right)<N W\left(x, b_{0}, u_{0}\right)$ (all workers unanimously prefer $b_{0}$ to $\left.b\right)$.

3. $N U\left(b, u_{0}\right)>N U\left(b_{0}, u_{0}\right)$ and $\exists \hat{x} \in\left[\bar{x}^{e}(b), \bar{x}_{0}^{e}\left(b_{0}\right)\right]$ such that $N W\left(x, b, u_{0}\right)>$ $N W\left(x, b_{0}, u_{0}\right)$ if $x>\hat{x}$ and $N W\left(x, b, u_{0}\right) \leq N W\left(x, b_{0}, u_{0}\right)$ if $x \leq \hat{x}$.

Proposition 3 establishes that unless workers are unanimously in favor or against increasing benefits (parts 1 and 2 , respectively), there is a conflict of interests whereby increasing benefits receives the support of the unemployed and the 'poorer' employed workers, and the opposition of the 'richer' employed workers (part 3). This case, which is the most interesting, is represented by figure 4 . At the initial unemployment benefits $b_{0}$, the employed workers are homogeneously distributed over the interval of distances (job types) $\left[0, \bar{x}_{0}^{e}\right]$. Although harm well-matched workers (the $N W$ schedule shifts to the left), the increase of the unemployment benefits from $b_{0}$ to $b$ makes better off all "poor" workers holding a job in the range $\left[\hat{x}, \bar{x}_{0}^{e}\right]$, as well as the unemployed. 
Remark 1. In both Lemma 3 and Proposition 3 we have considered the gains/losses from increasing $b$ from an initial level $b_{0}$. Although similar, the effects of reducing benefits are not perfectly symmetric. In this case, in fact, unless workers are unanimously in favor or against, all the employed workers will support the proposed reduction of insurance, while all the unemployed workers will be against it.

Remark 2. A more realistic analysis of the distributional issues should consider the effects of linear (or progressive) income taxation. If the insurance system is financed by income taxes, it is more likely that working poor and unemployed workers have common interests, even in blocking proposals of reducing $b$. The reason is that richer a worker the larger the cost of taxation. The formal analysis of the case of income taxation would be more involved, since throughout transitions the level of unemployment changes over time, thus the tax sequence which satisfies the budget constraint of the government is non-stationary.

In Proposition 2 we have established that when $\alpha=\beta$, the decentralized allocation with no benefits is Constrained Pareto optimum. The next Proposition establishes (proof in the Appendix) that in many economies, including those with $\alpha=\beta$, a union acting on behalf of both employed and unemployed workers would support the introduction of a positive degree of insurance. More in general, provided that the bargaining power of workers is not too large, the union would support the introduction of a positive level of unemployment benefits, even in cases where this reduces productive efficiency. To state this result formally, we will define by $T U_{W}\left(b, u_{0}\right)$ the total welfare of the employed worker, obtained by adding up the net wealth of all working agents equally weighted. Similarly, we define $T U_{U}, T U_{J}$ for the unemployed and firm owners, respectively. By evaluating all terms at a steadystate, we have: $T U_{W}\left(b, u_{0}\right)=\left(1-u_{0}\right) \int_{0}^{\bar{x}_{0}^{e}} N W\left(x, b, u_{0}\right) d x, T U_{U}\left(b, u_{0}\right)=u_{0} U\left(b, u_{0}\right)$, $T U_{J}\left(b, u_{0}\right)=\left(1-u_{0}\right) \int_{0}^{\bar{x}_{0}^{e}} J\left(x, b, u_{0}\right) d x$.

Proposition 4 Assume $b_{0}=0$. Then, $\exists \tilde{\beta}>\alpha$ such that, $\forall \beta<\tilde{\beta}$, $\frac{d T U_{U}\left(x, b, u_{0}\right)}{d b}+$ $\frac{d T U_{W}\left(x, b, u_{0}\right)}{d b}>0$ (the 'union' supports positive benefits). 


\section{Calibration: US vs. Europe.}

\subsection{Unemployment, output growth and inequality: the 70's vs. the 90 's.}

In this section we present the result of a rumerical solution of the model with calibrated parameters, which illustrates how the model can successfully mimic some features of the contrasting behavior of the labor markets in Western Europe and the United States in the last two decades.

To begin with, we note that the steady-state equilibrium given by (11) and (13) remains unchanged when neutral exogenous technical change is introduced. More precisely, if we let $b, c$ and $\eta(x)$ grow at the exogenous rate $g$, the solution characterized by Proposition 1 holds true unchanged. In particular, $\theta^{e}$ and $\bar{x}^{e}$ are independent of $g$, while wages and gross profits growing at a constant rate. For technical progress to be neutral the productivity of all matches has to grow at the same rate, i.e. $\eta_{t+k}(x)=e^{g k} \eta_{t}(x)$ for all $x$. If technical progress is non-neutral, the importance of mismatch changes over time, and affects the determination of the equilibrium.

We will consider two hypothetical economies which only differ by the extent of the unemployment insurance, parameterized by $b$. One economy, which will be denoted as $C 1$, will be assumed to have no unemployment insurance $\left(b_{1}=0\right)$. $C 1$ will be interpreted as a US-type laissez faire economy. Although unemployed workers receive in fact some benefits on both sides of the ocean, it has been argued (Mortensen, 1996) that the particular features of the American insurance program, like the very short duration and, especially, the requirement that the unemployed qualifies to receive benefits only if he has been working for some period in the previous year, imply that benefits in the US can have a negative rather than a positive effect on reservation wages. Motivated by this argument, we will regard zero benefits as a crude approximation to the US case. The other economy $(C 2)-$ which can be thought as a typical welfare state European country - has instead a standard system of benefit provision with an urlimited duration $\left(b_{2}>0\right)$. The two economies will be identical in all other parameters. The provision of unemployment benefit is financed by lump sum taxes paid by all workers, both employed and unemployed.

We assume that the two countries are initially at their respective steady-states, which we interpret as the situation in the early 70's. Then, both economies are hit 
by a common unanticipated shock which increases the importance of mismatch, by widening the productivity gap between the best $(x=0)$ and the worst $\left(x=\frac{1}{2}\right)$ job that a worker can perform. This shock can be interpreted as an episode of skillbiased technical change, as the following argument shows. Imagine that each agent has some specific skill which can be used in some occupations but not in others, hence each agent can be employed as a skilled worker by some firms but only as an unskilled worker by others. If skilled-biased technical change increases the relative productivity of skilled vs. unskilled workers, this can be captured in our model by an increase of the importance of mismatch. We will first report the statistics for the initial and the final period, which we interpret as the situation in the nineties. At the end of the section, we will also show the picture of the transitional dynamics of output and unemployment rates. As that picture shows, after twenty years from the occurrence of the shock the remaining effects of transitional dynamics are negligible.

We calibrate parameters as follows. We interpret a time period of unit length to be one quarter, and set the interest rate equal to 0.015 , implying an annual interest rate of $6 \%$. The separation rate is fixed at $d=0.04$, implying an average duration of a match of about six years. Although this job duration can appear as rather long - especially for the US - the assumption becomes more plausible once one realizes that we are only considering flows out of employment into unemployment and not job-to-job movements. We parameterize the mismatch function according to the linear specification given by equation (1), and we set the initial minimum productivity $\left(\eta_{l, 0}\right)$ equal to 2 , a normalization without any particular importance. Also, we set $a_{0}=0.5$ implying that each agent is $25 \%$ more productive in his best than in his worst occupation, and let $\gamma=4$, implying that each worker is to some extent skilled in one half of the possible employments. The bargaining power of each parties is one half, so $\beta=0.5$, corresponding to the symmetric Nash solution, and the elasticity of the matching function is constant with $\alpha=0.5$. Recall that when $\alpha=\beta$ the equilibrium path of the economy with no benefits maximizes the utility of a planner which is not concerned about equality. The hiring cost is assumed to be equal to foregoing the production flow of one low-productivity worker, i.e. $c_{0}=2$. Leisure is assumed to be worthless. In $C 2$, the welfare state economy, unemployed workers receive a subsidy equal to $50 \%$ of the wage paid to the worst paid workers (in both the initial and final period). Although this is probably less than what the unemployed typically receive in most European countries, it should be noted that in some economies (e.g. Spain) benefits have a limited duration. Additionally, 
accepting a job has normally a positive influence on the level of future benefits, hence we regard this figure as a realistic approximation of the impact of the benefits on the reservation wages.

We assume that there is an underlying trend of technical progress such that final period productivities, hiring costs and benefits are $20 \%$ larger than in the initial period $\left(\eta_{1}=c_{1}=2.4\right)$. The motivation for this trend is simply expositional, since it allows us to compare the results of the simulation with the real world figures. In particular, we calibrate parameters such that productivity growth in the US-type economy, $C 1$, is similar to the corresponding real US figure. With these parameters, in fact, productivity grows from one steady-state to another by about $20 \%$ in $C 1$; if we interpret the time span between the initial and the final point of observation as twenty years, we have a simulated yearly growth rate of productivity about one percent, which is close to the real figure. The shock takes the form of an increase of the parameter $a$ above its trend in both countries. In particular, $a$ is assumed to double, i.e. $a_{1}=1$. As a result, in the final steady-state the best matched worker's productivity exceed the worst matched worker's productivity by about $45 \%$.

Table 1 summarizes the results. In the initial period all workers search along the whole circle in both economies, i.e. $\bar{x}=\frac{1}{2}$. The resulting unemployment rates do not differ much, although, not surprisingly, unemployment is higher in $C 2(5.4 \%)$ than in $C 1(3.9 . \%)$. The average duration of unemployment is about four months in country 1 , and 5.7 months in country 2 . The wage distribution is very similar in the two countries, and so are output and productivity. Note that total output is initially slightly larger in country 1 than in country 2 . In the final steady-state, the situation looks dramatically different. The unemployment rate remains almost the same in country $1(3.8 \% \%)$ but increases substantially in country $2(11 \%)$. The reason is that the in $C 2$, where the cost of unemployment is lower due to insurance, agents find it optimal now to change their job search strategy. In particular, given the increased productivity gap, they become more selective in accepting jobs, and set the cut-off distance for the 'worst' acceptable job down to $\bar{x}=0.219$. In $C 1$, instead, where unemployment is a harder experience, agents still find it optimal to rush into any employment. As a result, although the vacancy-to-unemployment ratio does not change significantly in either countries, the average duration of unemployment - stable in country 1 - becomes twice as much as large in country 2 , going up to about one year. For the same reason, the percentage of long-term unemployed grows substantially in country 2 , and about half of the unemployed workers has to wait 
for more than six months before finding an acceptable job, while $23 \%$ has to wait for more than a year. ${ }^{9}$ Although workers experience longer unemployment spells in the welfare state economy, they are assigned more efficiently to jobs.

Table 1. Comparison between steady-states.

\begin{tabular}{|lc|ccc|}
\hline & & steady-state 1 & steady-state 2 & \% change \\
\hline \hline Cut-off, $\bar{x}$ & C1 & 0.5 & 0.5 & \\
& C2 & 0.5 & 0.219 & \\
\hline Unemployment rate & C1 & 3.9 & 3.8 & \\
& C2 & 5.4 & 11.0 & \\
\hline Average duration of & C1 & 4.1 & 4.0 & \\
unemployment (months) & C2 & 5.7 & 12.4 & 22.3 \\
\hline Average productivity & C1 & 2.05 & 2.56 & 30.6 \\
per employed & C2 & 2.07 & 2.81 & 22.4 \\
\hline Total output & C1 & 1.97 & 2.46 & \\
& C2 & 1.96 & 2.51 & 24.6 \\
\hline Percentage of unemployed & C1 & 13.1 & 12.5 & \\
with spell $\geq 6$ months & C2 & 22.9 & 48.2 & \\
\hline Percentage of unemployed & C1 & 1.7 & 1.6 & \\
with spell $\geq 12$ months & C2 & 5.3 & 23.2 & \\
\hline Percentage diff. & C1 & 12.0 & 19.3 & 7.3 \\
highest-lowest wage & C2 & 14.8 & 16.3 & 1.5 \\
\hline Percentage diff. & C1 & 9.7 & 15.8 & 6.1 \\
90th-10th wage percentile & C2 & 9.6 & 13 & 3.4 \\
\hline
\end{tabular}

As far as productivity growth is concerned, this is about $22 \%$ in country 1 and about $30 \%$ in country 2 . If we interpret the period length as of twenty years, this translates into average yearly growth rates of $1.1 \%$ and $1.5 \%$, respectively. The productivity gap is little less than half point percentage per year. The observed differential of productivity growth between the US and Europe is about $1.1 \%$ per

\footnotetext{
${ }^{9}$ The qualitative predictions of the model as to the change in the share of long-term unemployment are in accordance with the empirical evidence that this share has increased substantially in Europe, whereas it has exhibited hardly any change in the United States (see Ljungqvist and Sargent, 1996, for more details). On the other hand, the model is not very successful in predicting quantitatively the share of long term unemployment in Europe (while it fits better the evidence for the US). First, long-term unemployment was much higher in Europe than in the US already in the 70's, when our model predicts moderate differences. Second, the observed long-term unemployment in the nineties is larger than what is predicted by our model. In 1989 , about $70 \%$ of the unemployed in Europe had to wait for more than six months before finding a job (vs. $48.2 \%$ in our model), and about $50 \%$ had to wait for more than one year. Note, among the simplifications of the model, that here we ignore workers whose skills become obsolete and experience for this reason very long unemployment spells.
} 
laple 1 also snows that the model correctly preaicts the qualitative changes in wage inequality, although the quantitative effects are fairly small. Note that given the nature of agents' heterogeneity in our economies, where there are no workers which are intrinsically more productive than others, the model has predictions about within group rather than across group wage inequality. As we said, there is sound evidence that this wage inequality has grown more in the US than in Europe, and most existing theories - an exception is Acemoglu (1996a) - fail to predict this pattern. As shown by table 1, the model predicts a significantly larger increase in wage inequality in the economy without unemployment insurance than in the one with insurance, and this is true for both the ratio between the highest and lowest wage and the ratio between the 90 th and the 10 th percentile. The explanation of this difference is that while in country 2 many workers accept jobs which are completely unsuitable to their characteristics, and therefore receive a low wage, in country 1 poor matches are rejected. This shrinks the wage distribution. Thus, although the nature of technical change is intrinsically inequalizing, this is almost entirely offset by the changing attitude of job seekers in the welfare state economy. To the opposite, in the country with no insurance, the wider productivity gap is entirely passed through to increasing wage inequality between the lucky agents who have found good matches and the unlucky ones who have found bad matches.

Although the very stylized nature of the model forces us to treat with caution these quantitative results, it is encouraging to see that under a set of reasonable parameters the model predicts that "small" institutional differences can originate "large" observed differences. This result depends in the example presented on the fact that one of the two economies remains at a corner solution (like in figure 2), while the other "jumps" to an interior solution (like in figure 1). This is not strictly necessary. More in general, for obtaining effects of large size, it is necessary that the mismatch function be sufficiently "convex" so as to generate a larger response in the economy with than in the one without benefits.

\subsection{The welfare state dilemma: winners and loosers.}

The calibrated version of the model presented above can also be used to assess some of the distributional effects discussed in section 4.3. In particular, we will analyze how the gains and losses from the episode of skilled-biased technical change are distributed in the presence and in the absence of unemployment benefits. To this purpose, we consider the case of country C2, and evaluate the welfare (i.e. wealth) of all agents at the initial steady-state $\left(u_{0}=0.054, z_{0}=1.96, \bar{x}_{0}^{e}=0.5\right)$ immediately

\footnotetext{
${ }^{10}$ The assumption that unproductive jobs cannot be destroyed is crucial in determining the slow adjustment shown by figures 4 and 5 . If we assumed that firms can exit at no cost, both unemployment and output would adjust substantiallymore rapid.
} 
after the skill-biased technological shock. We compare the welfare of all agents under the benefit system of $C 2\left(b=b_{2}\right)$ and under the alternative case in which $b=b_{1}=0$. Since using the initial steady-state of $C 1$ gives almost identical results, we do not repeat the analysis for this case.

We first compute the difference in the after shock asset value of the labor income of employed and unemployed workers with and without benefits. This gives $W\left(x, b_{2}\right)-W(x, 0)=7.71$ for all employed workers such that $x \in[0,0.219]$ (recall that the after shock equilibrium cut-off is $\left.\bar{x}\left(b_{2}\right)=0.219\right) ; U\left(b_{2}\right)-U(0)=8.92$; $W\left(x, b_{2}\right)-W(x, 0) \in[7.71,8.92]$ for all 'poor' employed workers such that $x \in$ $[0.219,0.5]$. The present discounted cost of paying for funding the system borne by each worker is $T\left(b_{2}, 0.054\right)=8.57$. Clearly, $T=0$ if $b=0$.

As an inspection of the figures above immediately shows, the unemployed are better off with than without benefits (since $8.92>8.52$ ), while well-matched workers would prefer a no insurance system $(7.71<8.52)$. A large share of the working poor, however will also gain from the provision of benefits. In particular, it turns out that all employed workers with $x>0.242$ will be better off with than without insurance, whereas all 'richer' workers with $x<0.242$ will be worse off. Since employed workers are initially homogeneously distributed in the interval $x \in[0,0.5]$ this means that about $54 \%$ of the employed workers, together with all the unemployed ( $5.4 \%$ of the working population), are better off in the welfare state system. ${ }^{11}$ Remarkably, in this simple experiment $55 \%$ of the workforce would have chosen in the ' 70 's' a welfare state rather than a perfectly laissez-faire economy.

In summary, this section has shown that a model with search frictions and exante heterogeneity is consistent with large persistent differences in unemployment rates, and small differences in output growth. In the calibrated economies analyzed the different externalities which operate in presence of search frictions and ex-ante heterogeneity do not cause distortions $(\alpha=\beta)$. We have studied how the two economies - with and without welfare state - react to a skill-biased productivity shock. The economy with a system of unemployment insurance enjoys higher output at steady-state, faster productivity growth and a more equal distribution of wages and income. However, it pays this better long-run performance with a sharp

\footnotetext{
${ }^{11}$ However, it can also been show that if one starts at the final steady-state of C2 in table 1 (i.e. with $11 \%$ unemployment rate), only the unemployed would like to keep the system of benefit provision, while all employed workers would rather finish with it. In this case, the tax reduction from stopping financing the welfare state would more than compensate all employed workers for the wage reduction which this would imply.
} 
recession in the short-run, and with persistent unemployment. In the welfare state economy, the reservation wage raises substantially in response to the productivity shock, and the observed rate of job creation drops since the proportion of matches which are regarded as profitable by workers and firms also decreases. Finally, we have shown that the degree of unemployment insurance can originate significant differences in the distribution of gains and losses arising from unexpected technological shocks. For example, reducing the benefits has inequalizing effects on both income and wage distribution. These distributional effects, in turn, can help explain the different political support for introducing, or reforming, unemployment benefits policies.

\section{Conclusions}

Our search equilibrium model, where agents are differently skillful to perform different tasks, captures the main facts regarding the contrasting performance of US and European labor markets regarding increase wage inequality in US, increase unemployment in Europe and a similar growth rate in the last twenty years (i.e., a much higher productivity growth in Europe). There is a common driving force to this process, skilled-biased technological change, and just one institutional difference across these economies, the different level of unemployment insurance. This minimalist explanation contrasts with many arguments in the press, and in current research, regarding the 'main social problems affecting US and Europe at the end of the XX century.'

Our model can be viewed as a generalization -incorporating the mismatch dimensionof existing search equilibrium models (similar to Mortensen and Pissarides 1994), and our welfare results show that the Hosios-Pissarides 'elasticity condition' is also necessary and sufficient to guarantee an efficient assignment of workers to skillspecific jobs.

By postulating a perfect information model with risk-neutral agents and lumpsum taxation, we have abstracted from many features concerning the optimal design of unemployment benefit policies. For instance, we did not consider human capital depreciation due to persistent mismatch or unemployment, nor we considered the standard insurance component of unemployment benefits when agents are risk averse and cannot fully insure --possibly, for moral hazard and/or adverse selection reasons- 
against unemployment spells ${ }^{12}$. Neither we consider the effects on employment of an increase of fixed term unemployment benefits, by inducing long-term unemployed to accept -possibly, bad-jobs (as in Burdett 1979). Most of these effects will reinforce the positive role of some unemployment insurance policy and, therefore, strengthen some of our results.

Finally, our model could be extended to analyze other institutional features for example, job firing costs. In this paper, job destruction is an exogenous process. Although, European and US labor markets mainly differ in job creation rates, there are some differences in job destruction rates, too. In particular, during recessions job destruction is significantly higher in the US than in most (though not all) European countries. Assuming that the welfare state economy (C2) is also subject to firing restrictions could affect some results. In particular, if already formed matches are subject, ex-post, to productivity shocks, the existence of firing costs would increase mismatch in the welfare state economy, by forcing some unproductive matches not to be terminated. However, in our model firing costs would also induce firms (and workers) to reject some low productivity 'marginal' matches which would have been formed without these costs. The net effect on mismatch of introducing firing costs in our model is therefore ambiguous. We leave to future research this and other extensions.

\footnotetext{
${ }^{12}$ See, for example, Hansen and Imrohoroglu (1992), Hopenhayn and Nicolini (1995), Andolfatto and Gomme (1996) and Wang and Williamson (1996).
} 


\section{Appendix.}

Proof of Lemma 1. We will derive first (11), and then (12).

Using equations (6), (7) and (8), and eliminating $W(x)$ and $U$, we obtain:

$$
(r+d) \frac{\beta}{1-\beta} J(x)=w(x)-b-\frac{\beta}{1-\beta} 2 \theta q(\theta) \int_{0}^{\bar{x}} J(x) d x
$$

Then, we use (5) to replace the left hand-side expression. This gives the following expression for the wage schedules:

$$
w(x)=(1-\beta) b+\beta \eta(x)+2 \beta \theta q(\theta) \int_{0}^{\bar{x}} J(x) d x \quad \text { for } x \leq \bar{x} .
$$

Next, we integrate both sides of (34) and then substitute the expression obtained for $\int_{0}^{\bar{x}} J(x) d x$ into the right hand-side of (35). This gives:

$$
w(x)=(1-\beta) b+\beta \eta(x)+(1-\beta) \frac{2 \beta \bar{x} \theta q(\theta)}{r+d+2 \beta \bar{x} \theta q(\theta)}(\bar{\eta}(\bar{x})-b) \quad \text { for } x \leq \bar{x} .
$$

where $\bar{\eta}$ is defined in the text. By substituting (36) into (5), so as to eliminate the wage, we obtain:

$$
(r+d) J(x)=(1-\beta)\left[\frac{(r+d)(\eta(x)-b)+2 \beta \bar{x} \theta q(\theta)(\eta(x)-\bar{\eta}(\bar{x}))}{r+d+2 \beta \bar{x} \theta q(\theta)}\right] \text { for } x \leq \bar{x}
$$

Then, by imposing the condition that $J(\bar{x}) \geq 0$, we obtain (11) - where, clearly, either $J(\bar{x})=0$ or $\bar{x}=\frac{1}{2}$ and $J(x)>0$ for all $x \in\left[0, \frac{1}{2}\right]$.

To derive (12), observe that equations (5) and (9) imply (setting $j=0$ ) that $(r+d) J(\bar{x})=(1-\beta) \eta(\bar{x})-\beta c \theta \geq 0$, and this establishes the result. QED.

Proof of Lemma 2. Equation (13) follows from straightforward algebra using (3), $(4),(8)$ and (37), setting all time derivatives equal to zero. QED.

Comparison with Sattinger (1995). Consider a version of our model where $c=0$ (no cost of job creation) and the mass of firms is the same as that of workers $(M=1)$. Also, let $b_{l}=0$ for simplicity. Both workers and firms are uniformly distributed along the circle. Since posting a vacancy is costless, in equilibrium no firm remains idle and in the economy there are exactly as many vacancies as many unemployed workers at each moment of time. Formally, we have that $\theta=q(\theta)=1$. 
This is a version of Sattinger's model, with a continuum of perfectly symmetric types of workers and firms. The Bellman equations of this model are identical to those of section 2, except that (4) does no longer hold true - the value of firms with an open vacancy is positive - and, thus, the outside option of firms is not zero in the bargaining process (equation (8)). It can be verified through the procedure of section 3.1 that the equilibrium search cut-off satisfies the following condition: ${ }^{13}$

$$
(r+d) \eta\left(\bar{x}^{e}\right)-2 \bar{x}^{e}\left(\bar{\eta}\left(\bar{x}^{e}\right)-\eta\left(\bar{x}^{e}\right)\right)=0
$$

Equation (38) is also the solution of the planning problem (23) subject to (24) and (25) when we set $c=0$ and $\theta=1$. Thus, this version of Sattinger's model produces an efficient allocation of workers to job. However, our analysis shows that the same result does not hold true when job creation is costly and entry drive the value of firms with open vacancies to zero, except for the case in which the Hosios-Pissarides 'elasticity condition' $(\alpha=\beta)$ is satisfied.

Proof of Lemma 3. Part 1.From (5) and (9) we have, for all $x \in\left[0, \bar{x}^{e}(b)\right]$, $J(x, b)-J\left(x, b_{0}\right)=w\left(x, b_{0}\right)-w(x, b)=(1-\beta)\left(b_{0}-b\right)+\beta c\left(\theta\left(b_{0}\right)-\theta(b)\right)=$ $(1-\beta)\left[\eta\left(\bar{x}\left(b_{0}\right)\right)-\eta(\bar{x}(b))\right]<0$. (Note that this expression is independent of $x$; this observation will be useful in the proof of part 3 ). This inequality holds true, a fortioni, for $x>\bar{x}^{e}(b)$. Also, from (3), (4), (7), (8) and (9) we have $U(b)-$ $U\left(b_{0}\right)=(1-\beta)\left(b-b_{0}\right)-\frac{\beta}{1-\beta}\left[J(x, b)-J\left(x, b_{0}\right)\right]<0$. Finally, from $(6)$ we have that $W(x, b)-W\left(x, b_{0}\right)=w(x, b)-w\left(x, b_{0}\right)+d\left[U(b)-U\left(b_{0}\right)\right]>0$.

Part 2. From (8), we have that, for all $x \in\left[0, \bar{x}^{e}(b)\right] W(x, b)-W\left(x, b_{0}\right)=$ $U(b)-U\left(b_{0}\right)+\frac{\beta}{1-\beta}\left[J(x, b)-J\left(x, b_{0}\right)\right]$. Since, from part $1, J(x, b)-J\left(x, b_{0}\right)<0$, then $W(x, b)-W\left(x, b_{0}\right)<U(b)-U\left(b_{0}\right)$. Next, consider the range $x \in\left[\bar{x}^{e}\left(b_{0}\right), \bar{x}^{e}(b)\right]$. In this range, (6) and (10), imply that $W(x, b)=U(b)$. But, since $W\left(x, b_{0}\right)>U\left(b_{0}\right)$, then $W(x, b)-W\left(x, b_{0}\right)<U(b)-U\left(b_{0}\right)$ also in this range of $x$ 's.

Part 3. The proof of part 1 shows that in the range $x \in\left[0, \ddot{x}^{e}(b)\right], J(x, b)-$ $J\left(x, b_{0}\right)$ is independent of $x$. But, then, from (8), $W(x, b)-W\left(x, b_{0}\right)$ is also independent of $x$, and this proves part (a). To prove part (b) we consider first the case in which $x^{\prime} \in\left[0, \bar{x}^{e}(b)\right]$, and then the case in which $x^{\prime} \in\left[\bar{x}^{e}(b), \bar{x}^{e}\left(b_{0}\right)\right]$. In the former case: $W(x, b)-W\left(x, b_{0}\right)=U(b)-W\left(x, b_{0}\right)>U(b)-U\left(b_{0}\right)+\frac{\beta}{1-\beta}\left[J(x, b)-J\left(x, b_{0}\right)\right]=$

\footnotetext{
${ }^{13}$ The same condition can be obtained using Sattinger's procedure (see Sattinger, 1995, eq. 19, p. $294)$. Note that in this model the reservation wage of all workers is equal to $\beta \eta(\bar{x})$, the reservation profit of all firms is $\beta \eta(\bar{x})$, and the probability of a successful match is $2 \bar{x}$ ).
} 
$U(b)-U\left(b_{0}\right)+\frac{\beta}{1-\beta}\left[J\left(x^{\prime}, b\right)-J\left(x^{\prime}, b_{0}\right)\right]=W\left(x^{\prime}, b\right)-W\left(x^{\prime}, b_{0}\right)$. In the latter case: $W(x, b)-W\left(x, b_{0}\right)=U(b)-W\left(x, b_{0}\right)>U(b)-W\left(x^{\prime}, b_{0}\right)=W\left(x^{\prime}, b\right)-W\left(x^{\prime}, b_{0}\right)$. QED.

Proof of Proposition 3. Assume for simplicity that leisure is worthless $\left(b_{l}=0\right)$. Let $T W\left(b, u_{0}\right)=T U_{W}\left(b, u_{0}\right)+T U_{U}\left(b, u_{0}\right)+T U_{J}\left(b, u_{0}\right)$. Since agents are risk-neutral, then $T W\left(b, u_{0}\right)=\int_{0}^{\infty} e^{-r t}\left(y_{t}-c \theta_{t} u_{t}\right) d t$. Consider the case in which $\alpha=\beta$. Then, we know that $\frac{d T W\left(0, u_{0}\right)}{d b}=0$, by the Envelope Theorem. But, then, since $\frac{d T U_{J}\left(b, u_{0}\right)}{d b}<$ 0 for all $b$, it follows that $\frac{d T U_{U}\left(0, u_{0}\right)}{d b}+\frac{d T U_{\mathcal{W}}\left(0, u_{0}\right)}{d b}>0$. A fortiori, this will be true when $\beta<\alpha$, since in that case we have that $\frac{d^{\prime} T W\left(0, u_{0}\right)}{d b}>0$. Finally, continuity ensures that $\frac{d T U_{U}\left(0, u_{0}\right)}{d b}+\frac{d T U_{W}\left(0, u_{0}\right)}{d b}<0$ for some $\beta>\alpha$. QED. 


\section{References}

[1] Acemoglu, D., (1996a). 'Matching, Heterogeneity and the Evolution of Income Distribution.' CEPR Discussion Paper, No. 1345.

[2] Acemoglu, D. (1996c). 'Changes in Unemployment and Wage Inequality: An Alternative Theory and Some Evidence.' Mimeo, MIT.

[3] Acemoglu, D. (1997). 'Good Jobs versus Bad Jobs.' Mimeo, MIT.

[4] Acemoglu, D. and Shimer, R. (1997). 'Efficient Wage Dispersion.' Mimeo, MIT

[5] Alogoskoufis, G., Bean, C. et al. (1995). European Unemployment; Choices for Europe. Centre for Economic Policy Research Monitoring European Integration 5, London.

[6] Andolfatto, D. and Gomme, P. (1996). 'Unemployment Insurance and Labor-Market Activity in Canada.' Carnegie-Rochester Conference Series on Public Policy 47-82.

[7] Bertola, G. (1996). 'Uninsurable Risk, Efficiency and Labor Market Rigidities.' (mimeo) Universita di Torino.

[8] Bertola, G. and Ichino A. (1995). 'Wage Inequality and Unemployment: United States vs. Europe'. NBER Macroeconomic Annual.

[9] Bertola, G. and Rogerson, R. (1996). 'Institutions and Labor Reallocation.' (mimeo) University of Minnesota.

[10] Burdett, K. (1979). 'Unemployment Insurance Payments as a Search Subsidy: A Theoretical Analysis.' Economic Inquiry 42, 333-343.

[11] Diamond, P. (1981).'Mobility Costs, Frictional Unemployment, and Efficiency'. Journal of Political Economy, 89, 798-812.

[12] Diamond, P. (1982).'Aggregate Demand Management in Search Equilibrium'. Journal of Political Economy, 90, 881-94.

[13] Freeman, R. (1995). 'Are Wages Set in Bejing?' Journal of Economic Perspectives .

[14] Freeman, R. (1996). 'Toward an Apartheid Economy?' Harvard Business Review Sept.-Oct. 115-121.

[15] Greenwood, J., Hercowitz, Z. and Krusell, P. (1997). 'Long-Run Implications of Investment-Specific Techrological Change'. Rochester Center for Economic Research, WP No 420. Forthcoming, American Economic Review.

[16] Hansen, G. and Imrohoroglu, A. (1992). 'The Role of Unemployment Insurance in an Economy with Liquidity Constraints and Moral Hazard.' Journal of Political Economy, 100, 118-142.

[17] Hassler, J. and Rodriguez Mora, J. (1997). 'Employment Turnover and Unemployment Insurance.' Mimeo, IIES and Universitat Pompeu Fabra 
[18] Hosios, A. (1990).'On the efficiency of Matching and Related Models of Search and Unemployment.' Review of Economic Studies, 57.

[19] Jovanovic, B. (1979). 'Job Matching and the Theory of Turnover.' Journal of Political Economy, 87, 972-990.

[20] Krugman, P. (1994).'Europe jobless, America penniless.' Foreign Policy (Fall).

[21] Krusell, P., Ohanian, L., Rios Rull, V. and Violante, G. (1995).'Capital-Skill Complementarity and Inequality'. Mimeo, University of Pennsylvania.

[22] Levy, F. and Murnane R. (1992).'U.S. earnings levels and earnings inequality: A review of recent trends and proposed explanations.' Journal of Economic Literature, $30,1333-1381$.

[23] Layard, R., Nickell, S. and Jackman, R. (1991). Unemployment. Macroeconomic Performance and the Labour Market. Oxford University Press.

[24] Lillien, D. (1982).'Sectoral Shifts and Cyclical Unemployment'. Journal of Political Economy, 90, 777-93.

[25] Ljungqvist, L. and Sargent, T. (1996). 'The European Unemployment Dilemma.' Mimeo, Hoover Institution, Stanford.

[26] Manacorda, M. and Petrongolo, B. (1996). 'Skill Mismatch and Unemployment in OECD Countries.' Center for Economic Performance, LSE Disc. Paper No. 307.

[27] Marimon, R. and Zilibotti, F. (1997). 'Actual vs. Virtual Employment in Europe. Is Spain different?'. European Economic Review, forthcoming.

[28] Moen, E.R. (1995). 'A Search Model with Wage Announcement.' London School of Economics, Theoretical Economics Disc. Papers TE/95/280

[29] Mortensen, D. (1996a). 'Equilibrium Unemployment Theory: Determinants of the Natural Rate.' (mimeo) Northwestern University.

[30] Mortensen, D. (1996b). 'Employment and Wage Responses to Economic Fluctuations and Growth.' (mimeo) Northwestern University.

[31] Mortensen, D. (1996c). 'A Matching Model of Exchange Equilibrium.' (mimeo) Northwestern University.

[32] Mortensen, D. and Pissarides, D. (1994). 'Job Creation and Job Destruction in the Theory of Unemployment.' Review of Economic Studies, 61, 397-415.

[33] Moscarini, G., (1995). 'Fattening Economies.' Mimeo, MIT.

[34] Pheelan, C. and Trejos, A. (1995). 'Optimal Sectoral Shifts.' Mimeo, Northwestern University.

[35] Pissarides, D. (1990). Equilibrium Unemployment Theory. Basil Blackwell, London.

[36] Rendon S. (1996). Job search and asset Accumulation under Borrowing Constraints. Mimeo, New York University. 
[37] Sattinger, M. (1995).'Search and the Efficient Assignment of Workers to Jobs' International Economic Review, 36, 283-302.

[38] Saint Paul, G. (1997). 'Voting for Jobs: Policy Persistence and Unemployment'. CEPR Discusison Paper No. 1428.

[39] Shimer, R. (1995). 'Contracts in a Frictional Labor Market.' (mimeo) MIT.

[40] Wang, C. and Willamson, S. (1996). 'Unemployment Insurance with Moral Hazard in a Dynamic Economy.' Carnegie-Rochester Conference Series on Public Policy 47-82.

[41] Wright, R. (1986). 'The Redistributive Role of Unemployment Insurance and the Dynamics of Voting.' Journal of Public Economics, 31, 377-399. 